\title{
EarthN: A new Earth System Nitrogen Model
}

\author{
Benjamin W. Johnson ${ }^{1,2}$ Colin Goldblatt $^{2}$ \\ ${ }^{1}$ Department of Geological Sciences, University of Colorado, Boulder, Colorado, USA \\ ${ }^{2}$ School of Earth and Ocean Sciences, University of Victoria, Victoria, British Columbia, Canada
}

$5 \quad$ Key Points:

$6 \quad$ We model the evolution of nitrogen in all the reservoirs of Earth

$7 \quad$ Total, non-core $\mathrm{N}$ and plate tectonics exert strong control on atmospheric mass

s $\quad$ Weathering and the Great Oxidation event cause atmospheric draw-down

Corresponding author: B. W. Johnson, benjamin.w.johnson@colorado.edu 


\section{Abstract}

The amount of nitrogen in the atmosphere, oceans, crust, and mantle have important ramifications for Earth's biologic and geologic history. Despite this importance, the history and cycling of nitrogen in the Earth system is poorly constrained over time. For example, various models and proxies contrastingly support atmospheric mass stasis, net outgassing, or net ingassing over time. In addition, the amount available to and processing of nitrogen by organisms is intricately linked with and provides feedbacks on oxygen and nutrient cycles. To investigate the Earth system nitrogen cycle over geologic history, we have constructed a new nitrogen cycle model: EarthN. This model is driven by mantle cooling, links biologic nitrogen cycling to phosphate and oxygen, and incorporates geologic and biologic fluxes. Model output is consistent with large (2-4x) changes in atmospheric mass over time, typically indicating atmospheric drawdown and nitrogen sequestration into the mantle and continental crust. Critical controls on nitrogen distribution include mantle cooling history, weathering, and the total Bulk Silicate Earth+atmosphere nitrogen budget. Linking the nitrogen cycle to phosphorous and oxygen levels, instead of carbon as has been previously done, provides new and more dynamic insight into the history of nitrogen on the planet.

\section{Introduction}

Despite its importance and abundance in the Earth system, relatively little is known about the cycling of $\mathrm{N}$ throughout the major reservoirs of the Earth through time [Zerkle and Mikhail, 2017]. This is an important component of the Earth system, as the amount of $\mathrm{N}$ in the atmosphere can directly affect the climate [Goldblatt et al., 2009; Wordsworth and Pierrehumbert, 2013] as well as biologic productivity [Klingler et al., 1989]. Recent work has challenged the notion that $\mathrm{N}$ is primarily an atmospheric species, and instead the solid Earth may actually hold the majority of the planet's N budget [Marty, 2012; Halliday, 2013; Johnson and Goldblatt, 2015; Barry and Hilton, 2016; Mallik et al., 2018].

While the major biologic and geologic fluxes affecting $\mathrm{N}$ distribution are known, their behavior over Earth history is not constrained. Early descriptions of atmospheric $\mathrm{N}_{2}$ in the Precambrian admitted lack of data prevented speculation on what the atmospheric, and therefore mantle and continental crust, $\mathrm{N}$ content was at that time and how it has evolved since [Delwiche, 1977]. Subsequent work generally supports three hypotheses: steady-state atmospheric $\mathrm{N}$ mass over time [Marty et al., 2013], net mantle outgassing over time [Som et al., 2012, 2016], and net ingassing over time [Nishizawa et al., 2007; 
Goldblatt et al., 2009; Johnson and Goldblatt, 2015; Barry and Hilton, 2016; Mallik et al., 2018; Yoshioka et al., 2018]. Importantly, the assumption that atmospheric mass should be constant over Earth history is not an inherent property of the planet.

Preliminary modelling efforts considered sedimentary rocks as the main geologic storage and recycling vector for N [Zhang and Zindler, 1993; Berner, 2006] and compared $\mathrm{N}$ geochemically to the noble gases or carbon [Tolstikhin and Marty, 1998]. These studies found that there was little change $(<1 \%)$ in atmospheric $\mathrm{N}_{2}$ over at least the Phanerozoic [Berner, 2006] and possibly the majority of Earth history [Zhang and Zindler, 1993]. Additionally, while comparison to noble gases is valid for outgassing of oxidized magmas [Libourel et al., 2003], this comparison is not valid at subduction boundaries, as $\mathrm{N}$ is mostly found as $\mathrm{NH}_{4}^{+}$in subducted sediments [Bebout and Fogel, 1992] and oceanic crust [Busigny et al., 2011].

The geologic treatment of $\mathrm{N}$ in previous models may have missed some important behavior. Specifically, only considering sedimentary rocks as a sink for biologically processed N [Berner, 2006] based on N/C ratios does not include hydrothermal addition of $\mathrm{N}$ to oceanic crust (Fig. 1), which is observed in modern and older altered crust [e.g., Halama et al., 2014]. Sediment-only geologic $\mathrm{N}$ models also assume $\mathrm{N}$ and $\mathrm{C}$ behave similarly in subduction zones, which may not be true as $\mathrm{N}$ is likely found primarily as $\mathrm{NH}_{4}^{+}$geologically and $\mathrm{C}$ as organic $\mathrm{C}$ or $\mathrm{CO}_{3}^{2-}$. In addition, previous whole-Earth modeling [Tolstikhin and Marty, 1998] maintained a steady-state upper mantle, in terms of Nisotopes and concentration, by recycling of sedimentary and sea-water-sourced $\mathrm{N}$ from the surface and $\mathrm{N}$ from the lower mantle entrained in plumes. This approach is incomplete, as, again, surface $\mathrm{N}$ is subducted to the mantle as $\mathrm{NH}_{4}^{+}$and it is likely that the mantle as a whole is not layered. Therefore, a mechanism of "re-filling" the upper mantle from the lower mantle slowly over time appears untenable.

Studies of several modern subduction zones suggest more dynamic $\mathrm{N}$ evolution, and that there is overall net transport of $\mathrm{N}$ into the solid Earth, either the mantle or arcgenerated crust. Importantly, the $\mathrm{N}$ that survives the subduction barrier seems to mostly reside in the oceanic crust [Li et al., 2007; Mitchell et al., 2010]. There are many possible mineral hosts for such $\mathrm{N}$, typically found as $\mathrm{NH}_{4}^{+}$, during subduction, including $\mathrm{NH}_{4}^{+}$bearing feldspars, pyroxenes, beryls, and phlogopite in the mantle [Watenphul et al., 2009, 2010; Bebout et al., 2015] . Such crystalline N in altered crust appears to be more likely 


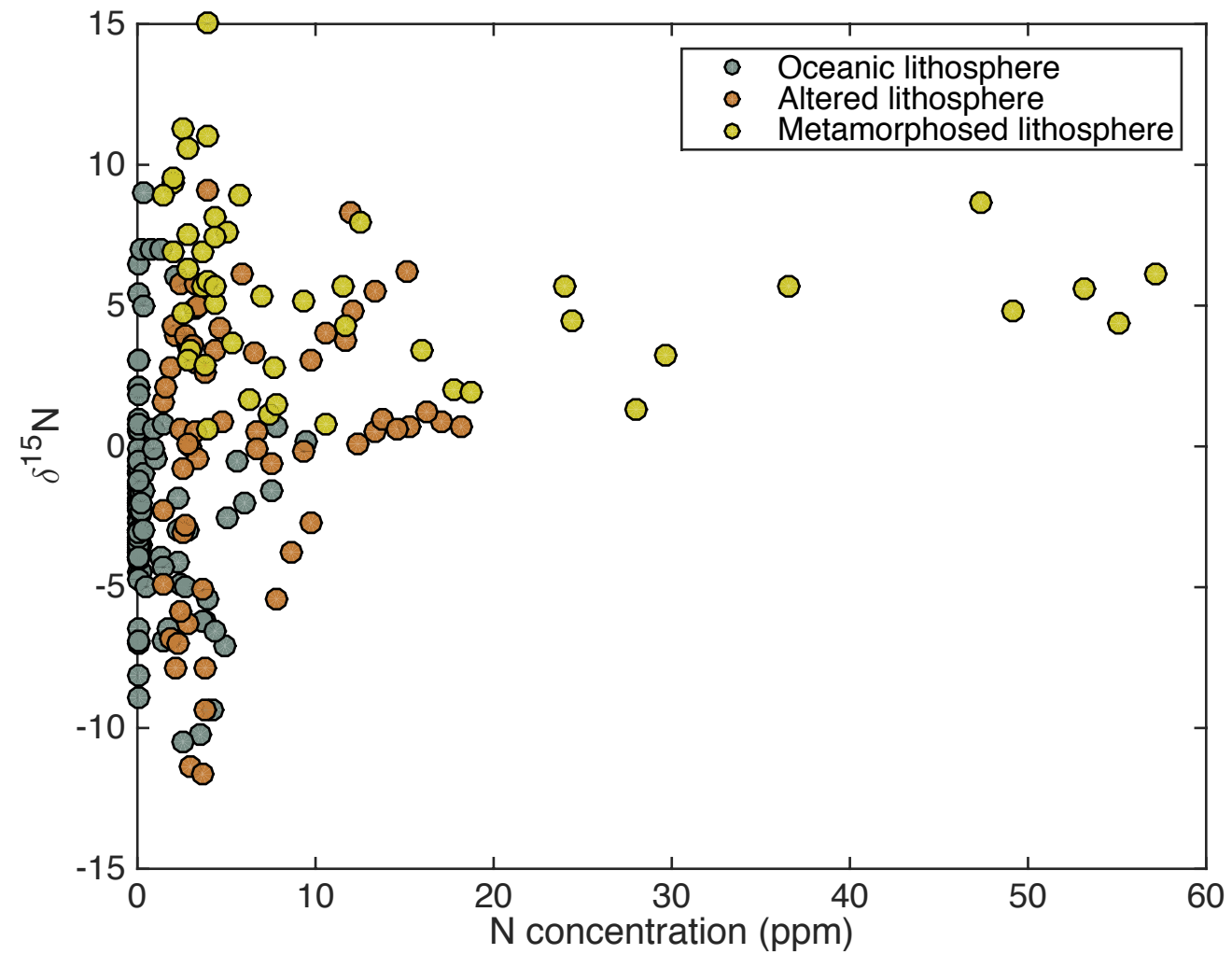

Figure 1: $\delta^{15} \mathrm{~N}$ plotted against $\mathrm{N}$ concentration (ppm) for oceanic lithosphere. Data are from the compilation of Johnson and Goldblatt [2015]. Shown are values from fresh lithosphere, altered lithosphere, and metamorphosed. Altered lithosphere has experienced temperatures of $<300{ }^{\circ} \mathrm{C}$ and metamorphosed samples have experienced temperatures $>300^{\circ} \mathrm{C}$. As oceanic lithosphere experiences alteration, $\mathrm{N}$ concentration increases, and initially depleted $\delta^{15} \mathrm{~N}$ values, with a mean of $-1.8 \%$ are enriched, indicating additional $\mathrm{N}$ is sourced from biologic material, which has $\delta^{15} \mathrm{~N}$ of 5\%. Altered lithosphere rocks include MORBs while metamorphosed lithosphere rocks include blueschists, eclogites, and metagabbros. 
to be carried into the mantle, whereas sedimentary $\mathrm{N}$ tends to return to the atmosphere at subduction zones [Fischer et al., 2002; Elkins et al., 2006; Halama et al., 2014].

As such, we are presented with a conundrum. Modeling efforts suggest that the atmosphere and solid Earth have remained in equilibrium in terms of $\mathrm{N}$-content over time. Contrastingly, geochemical evidence suggests there may be net transport of $\mathrm{N}$ from the surface to the mantle over time. It is from this conundrum that the construction of an Earth-system N cycle model, EarthN, follows.

Previous Earth system models implicitly have biologic processing [e.g., Stüeken et al., 2016], but none so far actually explicitly model the behavior of organisms. Biologic productivity and activity is the gate-keeper between the atmosphere and the solid Earth. Similarly, recent work has modeled the nitrogen cycle but without biology [Laneuville et al., 2018], to serve as a background for interpretations and models including biology. Nitrogen can cycle throughout the atmosphere, biosphere, sedimentary rocks, and crystalline Earth, thus constructing a model that integrates both biologic and geologic fluxes is critical for investigating the N-cycle over Earth history.

\section{Model setup}

The model is divided into a number of boxes. These are the atmosphere, three shallow ocean boxes (low-latitude, high-latitude, shelf), deep ocean, two biologically active sediment boxes (reactive shelf, reactive deep), sediments not in communication with the ocean (shelf, deep), and geologic reservoirs (mantle, oceanic crust, continental crust).

The model contains $\mathrm{N}$ as $\mathrm{N}_{2}, \mathrm{NO}_{3}^{-}$, and $\mathrm{NH}_{4}^{+}$, the last of which can be in the ocean or in geologic reservoirs. We also include other biologically relevant species: $\mathrm{PO}_{4}^{3-}$ and $\mathrm{O}_{2}$, as well as inorganic tracers: $\mathrm{K},{ }^{40} \mathrm{~K},{ }^{40} \mathrm{Ar}$, and ${ }^{36} \mathrm{Ar}$. Phosphate directly affects biologic productivity and $\mathrm{O}_{2}$ affects both productivity and which pathways of the biologic $\mathrm{N}$ cycle are in operation. Nitrogen is geochemically similar to $\mathrm{K}$ when found as $\mathrm{NH}_{4}^{+}$and geochemically similar to Ar when found as $\mathrm{N}_{2}$. As $\mathrm{K}$ and Ar are not biologically important elements, they serve as both a calibration and validation of the purely physical aspects of the model (Appendix C: ).

Biogeochemical fluxes are after Fennel et al. [2005], with a number of updates. Most geologic fluxes are driven by mantle cooling history after Korenaga [2010] and Padhi et al. [2012], which produces estimates of mantle temperature, crust production, and 


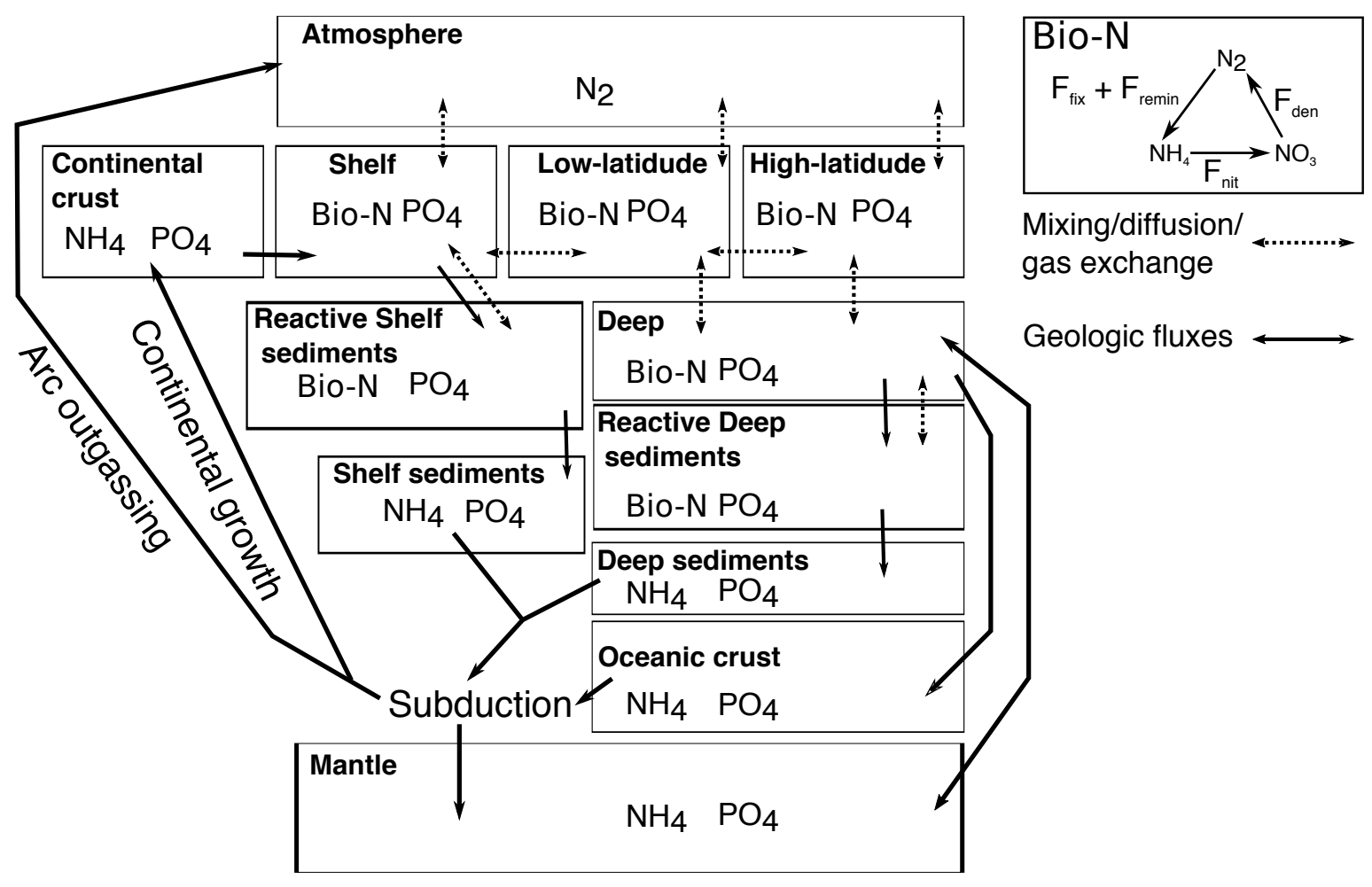

Figure 2: Earth system nitrogen cycle model schematic. In addition, we included $\mathrm{K},{ }^{40} \mathrm{~K},{ }^{40} \mathrm{Ar}$,

${ }^{36} \mathrm{Ar}$, and ${ }^{40} \mathrm{Ca}$ as checks on non-biologic cycles, though these are not shown here. 

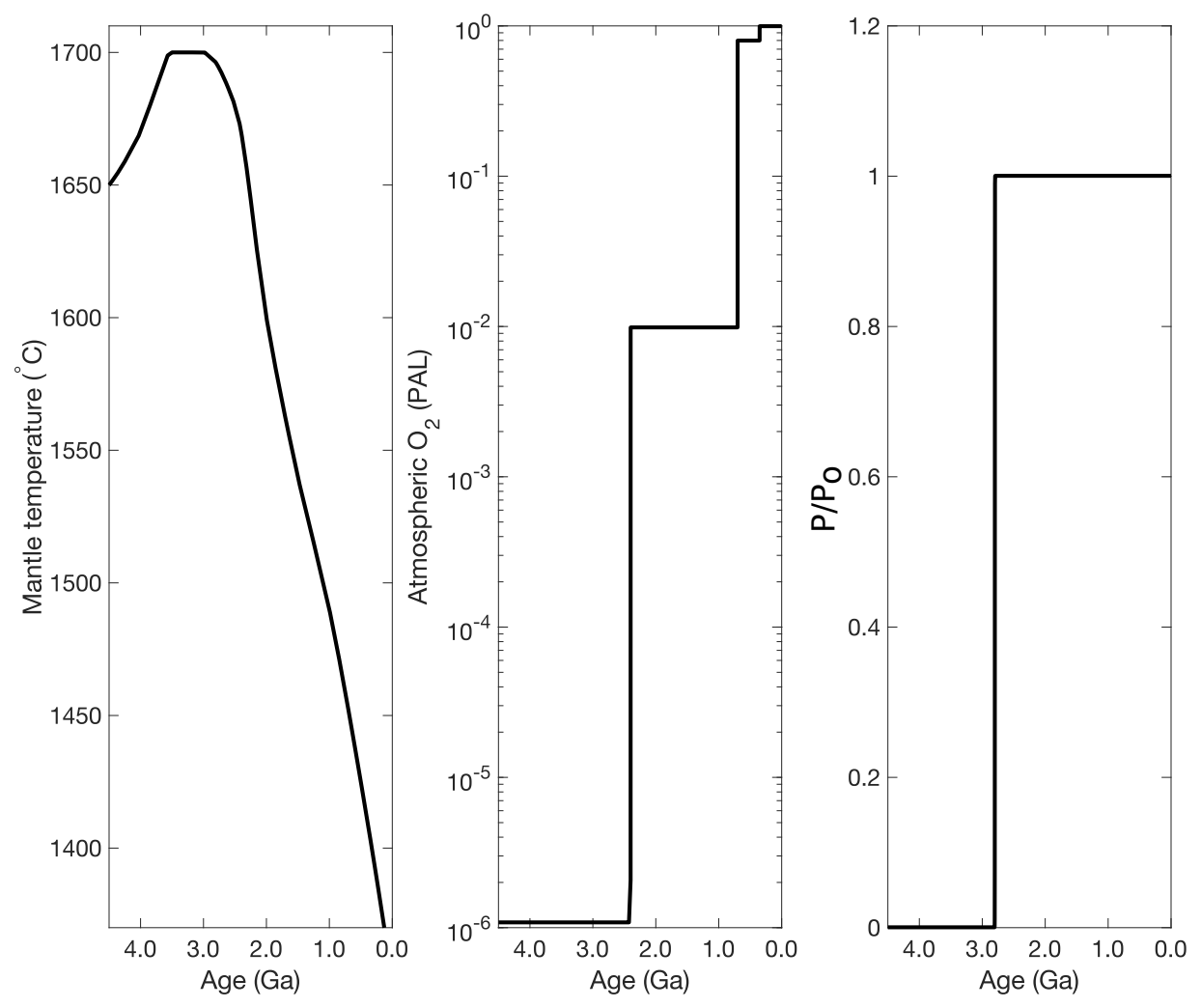

Figure 3: Model forcings, including average mantle potential temperature $\left({ }^{\circ} \mathrm{C}\right)[$ Korenaga, 2010], atmospheric $\mathrm{O}_{2}$ [e.g., Lyons et al., 2014], and primary productivity $(\mathrm{P})$ compared to modern $\left(\mathrm{P}_{\mathrm{o}}\right)$ constant [Goldblatt et al., 2006]. 
spreading rate through time (Fig. 3). Some runs have a constant proportion of subducted material retained to the mantle, and some link subducted fraction to mantle temperature.

The following is first a brief description of element cycles, then a detailed description of the model setup. We discuss each model box, the species contained within said box, and the fluxes that affect the amount of each species in the box. We use $R_{j}^{i}$ to represent reservoir in moles size of species $j$ in box $i$ and $C_{j}^{i}$ to represent the corresponding concentration. $F_{k}^{i}$ represents fluxes of type $k$ in box $i$ (Table 1). There are a number of fluxes that are sensitive to reactant concentration (e.g., Michaelis-Menten behavior), and are shown as $v_{l}$ where $l$ is specific to each sensitivity $v$. Parameter values are given in Table 2 and full differential equations are given in Appendix B.

\subsection{Brief element cycle descriptions}

The model Earth-system $\mathrm{N}$ cycle is as follows. Atmospheric $\mathrm{N}_{2}$ dissolves in the ocean, where it can be fixed (i.e., breaking the $\mathrm{N}$ triple bond) by bacteria. Fixed $\mathrm{N}$ then cycles biologically, and is released as waste or when organisms die. In oxygenated water, this reduced biologic $\mathrm{N}$ is quickly nitrified $\left(\mathrm{NH}_{4}^{+}\right.$to $\left.\mathrm{NO}_{3}^{-}\right)$by bacteria; in anoxic water it remains as $\mathrm{NH}_{4}^{+}$. Some organic material sinks into the deep ocean, where most gets remineralized into either $\mathrm{NH}_{4}^{+}$or $\mathrm{NO}_{3}^{-}$depending on $\mathrm{O}_{2}$ levels, and a small portion sinks to the sediments. In the sediments, organic matter breaks down and bonds as $\mathrm{NH}_{4}^{+}$into clays and other K-bearing minerals. Some $\mathrm{N}$ also gets incorporated into oceanic crust during hydrothermal alteration. Sediments and oceanic crust get subducted, with a portion of $\mathrm{N}$ going into the mantle, a portion outgassed to the atmosphere, and a portion incorporated into arc-generated crust. Mantle $\mathrm{N}$ can be outgassed at mid-ocean ridges. Continental crust $\mathrm{N}$, organic or inorganic, can be weathered and added back to the ocean.

Phosphate enters the ocean due to continental weathering and from mid-ocean ridge outgassing. In the shallow ocean, it is consumed during primary production, both that based on already fixed $\mathrm{N}$ and that based on fixing new $\mathrm{N}$. It is then exported to the deep or lower shelf ocean, where it is either remineralized or buried in sediments. Sedimentary and altered oceanic crust $\mathrm{PO}_{4}^{3-}$ can be subducted. A portion goes into the mantle, and a portion into the continental crust.

The model cycles for $\mathrm{K}$ and Ar are only affected by physical, non-biologic processing. All isotopes of both elements mix between ocean boxes, and ${ }^{40} \mathrm{~K}$ decays to ${ }^{40} \mathrm{Ar}$ in 
every box where it is found. Continental weathering releases $\mathrm{K}$ to the shelf ocean, and Ar to the atmosphere. Air sea gas exchange moves Ar from the surface ocean boxes to the atmosphere. Both species can get incorporated into oceanic crust during hydrothermal alteration, and $\mathrm{K}$ can be incorporated into sediments. Again, during subduction, some $\mathrm{K}$ and Ar is transported to the mantle, and the remainder either goes to the continental crust (K) or the atmosphere (Ar). Both are added to the deep ocean during mid-ocean ridge outgassing.

\section{$2.2{ }^{40}$ K-decay}

Radioactive decay of ${ }^{40} \mathrm{~K}$ produces ${ }^{40} \mathrm{Ar}$ in all boxes where ${ }^{40} \mathrm{~K}$ is present:

$$
F_{\mathrm{rd}}^{i}=\lambda X_{40 \mathrm{~K}} R_{40 \mathrm{~K}}^{i}
$$

for $i=\{$ all ocean and geologic boxes $\}$ where $X_{40 \mathrm{~K}}$ is the proportion of decays that form ${ }^{40} \mathrm{Ar}$ and $\lambda$ is the decay constant of ${ }^{40} \mathrm{~K}$.

\subsection{Atmosphere}

The atmosphere contains $\mathrm{N}_{2}, \mathrm{O}_{2}$, and both isotopes of $\mathrm{Ar} . \mathrm{N}_{2},{ }^{40} \mathrm{Ar}$, and ${ }^{36} \mathrm{Ar}$ exchange with the ocean following stagnant-lid gas exchange [Liss and Slater, 1974], with fluxes positive in the direction of sea to air:

$$
F_{\mathrm{as}}^{i}=u_{1, j} A^{i}\left(C_{j}^{i}-H_{j} P_{j}\right)
$$

for boxes $i=\{$ low, high, shelf $\}$ oceans and species $j=\left\{\mathrm{N}_{2},{ }^{40} \mathrm{Ar},{ }^{36} \mathrm{Ar}, \mathrm{O}_{2}\right\} . u_{1, j}$ is piston velocity in $\mathrm{m} \mathrm{yr}^{-1}$ calculated by dividing the diffusion constant $\left(D_{i}\right)$ by thickness of stagnant boundary $\left(z_{\text {film }}\right) ; A^{i}$ is ocean box surface area $\left(\mathrm{m}^{2}\right) ; C_{i}^{j}$ is concentration of species $j$ in box $i$; $H^{j}$ is Henry's law constant for species $j\left(\mathrm{~mol} \mathrm{~L}^{-1} \mathrm{~atm}^{-1}\right)$; and $P^{j}$ is partial pressure of gas $j$, calculated as:

$$
P_{j}=\frac{R_{j}^{\mathrm{atm}}}{n_{\mathrm{a}}}
$$

where $n_{\mathrm{a}}$ is the number of moles corresponding to one atmosphere pressure (Table 2).

Gasses are also added to the atmosphere via outgassing at arcs and both isotopes of Ar are added from continental crust weathering (Sec. 2.5). 
Table 1: Full list of fluxes used in model. Shown are flux symbol, brief description, and which model species are affected by each flux. In ocean boxes (low, high, shelf, deep), all species includes $\mathrm{NO}_{3}^{-}$and $\mathrm{NH}_{4}^{+}$, while in geologic boxes, all species just includes moles of $\mathrm{N}$.

\begin{tabular}{|c|c|c|}
\hline Flux & Description & Species affected \\
\hline$F_{\text {rd }}$ & radioactive decay & ${ }^{40} \mathrm{Ar},{ }^{40} \mathrm{~K}$ \\
\hline$F_{\text {as }}$ & air-sea gas exchange & ${ }^{40} \mathrm{Ar},{ }^{36} \mathrm{Ar}, \mathrm{N}_{2}$ \\
\hline$F_{\text {mix }}$ & water-mixing & all species \\
\hline$F_{\text {nit }}$ & nitrification & $\mathrm{NO}_{3}^{-}, \mathrm{NH}_{4}^{+}$ \\
\hline$F_{\text {denit }}$ & denitrification & $\mathrm{NO}_{3}^{-}, \mathrm{N}_{2}$ \\
\hline$F_{\text {oldN }}$ & production from fixed $\mathrm{N}$ & $\mathrm{NO}_{3}^{-}, \mathrm{NH}_{4}^{+}, \mathrm{PO}_{4}^{3-}$ \\
\hline$F_{\text {newN }}$ & production from newly fixed $\mathrm{N}$ & $\mathrm{N}_{2}, \mathrm{PO}_{4}^{3-}$ \\
\hline$F_{\text {out }}$ & export from shallow ocean boxes & $\mathrm{NO}_{3}^{-}, \mathrm{NH}_{4}^{+}, \mathrm{N}_{2}, \mathrm{PO}_{4}^{3-}$ \\
\hline$F_{\text {remin }}$ & remineralization in shelf and deep & $\mathrm{NO}_{3}^{-}, \mathrm{NH}_{4}^{+}, \mathrm{PO}_{4}^{3-}$ \\
\hline$F_{\text {bur }}$ & burial in sediments & $\mathrm{N}, \mathrm{PO}_{4}^{3-}$ \\
\hline$F_{\text {seddif }}$ & diffusion into sediments, out of water & $\mathrm{NH}_{4}^{+}$ \\
\hline$F_{\text {sub }}$ & subduction of crust and sediments & all species \\
\hline$F_{\text {subT }}$ & total subduction & all species \\
\hline$F_{\text {subnet }}$ & net subduction & all species \\
\hline$F_{\text {hydro }}$ & hydrothermal alteration & all species \\
\hline$F_{\mathrm{w}}$ & weathering & all species \\
\hline$F_{\mathrm{cg}}$ & continental growth & all species \\
\hline$F_{\text {scg }}$ & continental growth from shelf sediments & all species \\
\hline$F_{\text {ogarc }}$ & outgassing-arcs & all species \\
\hline$F_{\text {ogmor }}$ & outgassing-mid ocean ridge & all species \\
\hline
\end{tabular}


Oxygen levels are prescribed. Levels start at $10^{-6}$ present atmospheric level (PAL $\left.=2 \times 10^{19} \mathrm{~mol}\right)$ through the Hadean and Archean. . Atmospheric $\mathrm{O}_{2}$ increases to 0.01 PAL over $100 \mathrm{Myr}$ at $2.4 \mathrm{Ga}$, then to $0.8 \mathrm{PAL}$ at $0.630 \mathrm{Ga}$ (beginning of the Ediacaran). Oxygen rises to modern levels at $0.418 \mathrm{Ga}$ (Devonian). Surface ocean $\mathrm{O}_{2}$ concentrations are calculated assuming a Henry's law equilibrium.

\subsection{Ocean}

The ocean is divided into four boxes: high- and low-latitude shallow ocean, shelf ocean, and deep ocean. All species in the model exist in the ocean. There are a number of fluxes, both physical and biogeochemical that occur. Some can occur in all boxes, and some only in specific boxes. Broadly, primary production occurs in shallow ocean boxes, remineralization and burial occur in deep and shelf boxes, and nitrification and denitrification occur in all boxes.

\subsubsection{All boxes}

There is physical water mixing between all ocean boxes. Mixing out of an ocean box is simply the product of concentration of species $j$ in box $i$ and the sum of the water fluxes $\left(\Delta^{i-i *}\right.$, in $\left.\mathrm{L} \mathrm{yr}^{-1}\right)$ between box $i$ and all other boxes $(i *)$. Mixing in to box $i$ is the sum of the product of the concentrations of species $j$ in each other box $(i *)$ and the water flux between box $i$ and each other box $\left(\Delta^{i-i *}\right)$ :

$$
F_{\mathrm{mix}, j}^{i}=-C_{j}^{i} \sum_{i *} \Delta^{i-i *}+\sum_{i *} C_{j}^{i *} \Delta^{i-i *}
$$

If, for example, $i=\{$ low $\}$, then $i *=\{$ high, shelf, deep $\}$, and $\Delta^{i-i *}$ is mixing between low and high, low and shelf, and low and deep boxes.

Nitrification occurs in all boxes. The rate of nitrification is dependent on $\mathrm{O}_{2}$ and $\mathrm{NH}_{4}^{+}$concentrations:

$$
\begin{gathered}
v_{\mathrm{Onit}}^{i}=\frac{C_{\mathrm{O} 2}^{i}}{C_{\mathrm{O} 2}^{i}+K_{\mathrm{Oni}}} \\
v_{\mathrm{NOnit}}^{i}=\frac{C_{\mathrm{NH} 4}^{i}}{C_{\mathrm{NH} 4}^{i}+K_{\mathrm{Nni}}}
\end{gathered}
$$


The full equation can be parameterized as:

$$
F_{\text {nit }}^{i}=\mu_{\mathrm{NH} 4} v_{\text {Onit }}^{i} v_{\mathrm{NHnit}}^{i} R_{\mathrm{NH} 4}^{i}
$$

for box $i=\{$ low, high, shelf, deep $\}$, and where $K_{\text {Oni }}$ is the half-saturation uptake concentration of $\mathrm{O}_{2}$ used in nitrification $(20 \mu \mathrm{M}), K_{\mathrm{Nni}}$ is half-saturation uptake concentration of $\mathrm{O}_{2}$ used in nitrification $(100 \mu \mathrm{M})$, and $\mu_{\mathrm{NH} 4}$ is a rate constant $\left(\mathrm{yr}^{-1}\right)$.

Denitrification can also occur in every ocean box $(i=\{$ low, high, shelf, deep $\})$. It has been observed to follow first-order rate kinetics, with a half-saturation $\mathrm{NO}_{3}^{-}$concentration $\left(K_{\mathrm{d}}\right)$ of $8 \mu \mathrm{M}$ [Goering, 1985; Evrard et al., 2013]:

$$
v_{\mathrm{NOde}}^{i}=\frac{C_{\mathrm{NO} 3}^{i}}{C_{\mathrm{NO} 3}^{i}+K_{\mathrm{d}}}
$$

In contrast to nitrification, denitrification only occurs at low $\mathrm{O}_{2}$ levels [Crowe et al., 2012; Dalsgaard et al., 2014], herein parameterized as a Michaelis-Menten type reaction:

$$
v_{\mathrm{Ode}}^{i}=\frac{C_{\mathrm{O} 2}^{i}}{C_{\mathrm{O} 2}^{i}+O_{\text {inhib }}}
$$

where $O_{\text {inhib }}$ is $205 \mathrm{nM}$ [Dalsgaard et al., 2014]. Thus, we parameterize denitrification as:

$$
F_{\mathrm{den}}^{i}=\left(1-v_{\mathrm{Ode}}^{i}\right) v_{\mathrm{NOde}}^{i} R_{\mathrm{NO} 3}^{i}
$$

\subsubsection{Shallow ocean}

Primary production occurs in all shallow ocean boxes ( $i=\{$ low, high, shelf $\})$. There are two types of productivity [Fennel et al., 2005]: that based on already fixed $\mathrm{N}\left(F_{\text {oldN }}\right)$ and that based on newly-fixed $\mathrm{N}_{2}\left(F_{\text {newN }}\right)$. These two fluxes together equal total export production $\left(F_{\mathrm{ExT}}^{i}\right)$. The proportion of $F_{\text {oldN }}$ to $F_{\text {newN }}$ depends, in part, on the N:P ratio, which we assume will always move towards Redfield (i.e., 16:1). We parameterize this relationship as:

$$
L_{\mathrm{R}}^{i}=\frac{N / P^{i}}{N / P^{i}+K_{\mathrm{NP}}}
$$
where $K_{\mathrm{NP}}$ is 8 . 
In addition, $F_{\text {oldN }}$ can be $\mathrm{PO}_{4}^{3-}$ or N-limited:

$$
\begin{aligned}
& L_{\mathrm{N}}^{i}=\frac{N_{\text {all }}^{i}}{N_{\mathrm{all}}^{i}+K_{\mathrm{N}}} \\
& L_{\mathrm{P}}^{i}=\frac{C_{\mathrm{PO} 4}^{i}}{C_{\mathrm{PO} 4}^{i}+K_{\mathrm{P}}}
\end{aligned}
$$

where $K_{\mathrm{N}}$ and $K_{\mathrm{P}}$ are the half saturation uptake values for $\mathrm{N}$ and $\mathrm{PO}_{4}^{3-} . N_{\text {all }}^{i}$ is the sum of $C_{\mathrm{NH} 4}^{i}$ and $C_{\mathrm{NO} 3}^{i}$ in box $i$. We also assume productivity $(P)$ was 1000 times less efficient before the evolution of oxygenic photosynthesis:

$$
\frac{P}{P_{o}}=\left(\left(1+1 \times 10^{-3}\right)+\tanh \left(\left(t-\operatorname{Phot}_{\text {On }}\right) / 0.1\right)\right) \times 0.5 ;
$$

where $P_{o}$ is modern primary productivity efficiency (1) and Phot ${ }_{\text {On }}$ is the age of oxygenic photosynthesis evolution.

Thus, $F_{\text {oldN }}^{i}$ is:

$$
F_{\text {oldN }}^{i}=\frac{P}{P_{o}} L_{\mathrm{R}}^{i} L_{\mathrm{N}}^{i} L_{\mathrm{P}}^{i} R_{\mathrm{PO} 4}^{i} / \tau_{\mathrm{prod}}
$$

for boxes $i=\{$ low, high, shelf $\}$ and where $\tau_{\text {prod }}$ is a production timescale, set to $0.5 \mathrm{yr}$.

Production from $\mathrm{N}_{2}$ fixing is $\mathrm{PO}_{4}^{3-}$-limited, but also depends on $\mathrm{N}$-concentrations and partial pressure of $\mathrm{N}_{2}$. There is a Michaelis-Menten relationship to partial pressure [Klingler et al., 1989]:

$$
v_{\text {fix }}=\frac{R_{\mathrm{N} 2}^{\mathrm{atm}}}{R_{\mathrm{N} 2}^{\mathrm{atm}}+K_{\mathrm{f}}}
$$

where $K_{\mathrm{f}}$ is $9.87 \times 10^{18}$ moles, or about the equivalent of 50 mbar pressure.

Thus, total production based on newly-fixed $\mathrm{N}_{2}$ is:

$$
F_{\text {newN }}^{i}=\frac{P}{P_{o}}\left(1-L_{\mathrm{R}}^{i}\right) L_{\mathrm{P}}^{i} v_{\text {fix }} R_{\mathrm{PO}}^{i} / \tau_{\text {prod }}
$$

We note that we do not include abiotic N-fixing in our model [e.g., Navarro-González et al., 2001]. Total export production $\left(F_{\mathrm{ExT}}^{i}\right)$ from boxes $i=\{$ low, high, shelf $\}$ is the sum of $F_{\text {oldN }}^{i}$ and $F_{\text {newN }}^{i}$. Export production in both the low- and high-latitude boxes go to the 
deep ocean, and shelf export stays in the shelf box. Phosphate loss $\left(F_{\mathrm{out}, \mathrm{PO} 4}^{i}\right)$ from shallow boxes is equal to $F_{\text {ExT }}^{i}$. Fixed $\mathrm{NO}_{3}^{-}$and $\mathrm{NH}_{4}^{+}$losses are equal to:

$$
F_{\text {out }, j}^{i}=16 F_{\text {oldN }}^{i} \frac{C_{j}^{i}}{N_{\text {all }}^{i}}
$$

for $j=\left\{\mathrm{NO}_{3}^{-}, \mathrm{NH}_{4}^{+}\right\}$and $\mathrm{N}_{2}$ loss is:

$$
F_{\text {out,N2 }}^{i}=16 F_{\text {newN }}^{i}
$$

as we keep track of moles $\mathrm{N}$, not moles $\mathrm{N}_{2}$.

\subsubsection{Shelf ocean, deep ocean, reactive shelf and deep sediments}

$\mathrm{PO}_{4}^{3-}$ and $\mathrm{N}$ can be remineralized or buried, and $\mathrm{K}$ can be buried in sediments. The efficiency of remineralization depends on oxygen concentration:

$$
\begin{gathered}
f_{\text {aerobic }}^{i}=\frac{C_{\mathrm{O} 2}^{i}}{C_{\mathrm{O} 2}^{i}+K_{\mathrm{O}}} \\
F_{\text {reminfrac, } \mathrm{j}}^{i}=0.9 f_{\text {aerobic }}^{i}+0.7\left(1-f_{\text {aerobic }}^{i}\right) .
\end{gathered}
$$

for boxes $i=\{$ shelf ocean, deep ocean, reactive shelf sediments, reactive deep sediments $\}$ and species $j=\left\{\mathrm{PO}_{4}^{3-}, \mathrm{NH}_{4}^{+}\right\}$and where $K_{\mathrm{O}}$ is $50 \mu \mathrm{M}$. The values in the above equations are tuned to have aerobic remineralization convert $90 \%$ of export production, while only $70 \%$ gets remineralized under anaerobic conditions. Nitrogen remineralization and burial is assumed to be in Redfield ratio (i.e.,16:1) compared to $\mathrm{PO}_{4}^{3-}$. Nitrogen is remineralized as $\mathrm{NH}_{4}^{+}$.

Export production from the high and low-latitude shallow boxes is remineralized in the deep ocean and export production in the shelf ocean is remineralized in the shelf ocean. That which is not remineralized in the deep or shelf ocean boxes goes to the reactive deep and shelf sediments, respectively. Remineralization can occur in these reactive sediment boxes, with anything not remineralized buried to the non-reactive deep and shelf sediments. Additionally, nitrification, denitrification, and diffusion occur in the reactive sediment layers. Diffusion $\left(F_{\text {diff }}^{i}\right)$ is parameterized as:

$$
F_{\mathrm{diff}, j}^{i}=D_{j}\left(C_{\mathrm{O} 2, j}^{i *}-\frac{C_{\mathrm{O} 2, j}^{i}}{D_{\text {length }}}\right) S A^{i *}
$$


for boxes $i=\{$ Reactive shelf sediments, reactive deep sediments $\}$ and $i *=\{$ shelf ocean, deep ocean $\}$. $D_{j}$ is the diffusion constant and $D_{\text {length }}$ is diffusive length, which is set to $0.01 \mathrm{~m}$.

Table 2: All model constants, shown with references. References are: H14 [Haynes et al., 2014], S99 [Sander, 1999], F05 [Fennel et al., 2005], LS74 [Liss and Slater, 1974], B16 [Bristow et al., 2016], D14 [Dalsgaard et al., 2014], G85 [Goering, 1985], E13 [Evrard et al., 2013], K89 [Klingler et al., 1989], JG15 [Johnson and Goldblatt, 2015], W10 [Winter, 2001], and K10 [Korenaga, 2010]

\begin{tabular}{|c|c|c|c|}
\hline Parameter & Definition & Value & Reference \\
\hline$\lambda$ & decay constant of ${ }^{40} \mathrm{~K}\left(\mathrm{yr}^{-1}\right)$ & $5.543 \times 10^{-10} \mathrm{yr}^{-1}$ & $\mathrm{H} 14$ \\
\hline$X_{40}$ & fraction of decay producing ${ }^{40} \mathrm{Ar}$ & 0.1072 & $\mathrm{H} 14$ \\
\hline$D_{\mathrm{N}_{2}}$ & Diffusion constants $\left(\mathrm{cm}^{2} \mathrm{~s}^{-1}\right)$ & $1.88 \times 10^{-5}$ & $\mathrm{H} 14$ \\
\hline$D_{\mathrm{Ar}}$ & & $1.88 \times 10^{-5}$ & H14 \\
\hline$D_{\mathrm{O}_{2}}$ & & $2.5 \times 10^{-5}$ & $\mathrm{H} 14$ \\
\hline$D_{\text {length }}$ & Diffusion length & $0.01 \mathrm{~m}$ & \\
\hline$H_{\mathrm{N}_{2}}$ & Henry's law constants (mol L $\mathrm{matm}^{-1}$ ) & $1.3 \times 10^{-3}$ & S99 \\
\hline$H_{\mathrm{Ar}}$ & & $6.1 \times 10^{-4}$ & S99 \\
\hline$H_{\mathrm{O}_{2}}$ & & $6.1 \times 10^{-4}$ & S99 \\
\hline$n_{a}$ & moles equal to one atm pressure & $1.72 \times 10^{20}$ & this study \\
\hline$d$ & ocean depth (m) & 4500 & F05 \\
\hline$z_{\text {film }}$ & stagnant lid thickness (m) & $1.5 \times 10^{-5}$ & LS74 \\
\hline$A^{\text {high }}$ & ocean box surface area $\left(\mathrm{m}^{2}\right)$ & $2.3 \times 10^{12}$ & F05 \\
\hline$A^{\text {low }}$ & & $2.3 \times 10^{12}$ & F05 \\
\hline$A^{\text {shelf }}$ & & $5.1 \times 10^{11}$ & F05 \\
\hline$V^{\text {high }}$ & ocean box volumes (L) & $9 \times 10^{18}$ & F05 \\
\hline$V^{\text {low }}$ & & $9 \times 10^{18}$ & F05 \\
\hline$V^{\text {shelf }}$ & & $1.5 \times 10^{18}$ & F05 \\
\hline$V^{\text {deep }}$ & & $8.1 \times 10^{20}$ & F05 \\
\hline$\Delta^{\text {low-high }}$ & mixing between ocean boxes (Sv) & 30 & F05 \\
\hline$\Delta^{\text {low-shelf }}$ & & 30 & F05 \\
\hline$\Delta^{\text {low-deep }}$ & & 30 & F05 \\
\hline$\Delta^{\text {high-shelf }}$ & & 30 & F05 \\
\hline
\end{tabular}


Table 2 Model Constants - continued from previous page

\begin{tabular}{|c|c|c|c|}
\hline Parameter & Definition & Value & Reference \\
\hline$\Delta^{\text {high-deep }}$ & & 50 & F05 \\
\hline$\Delta^{\text {shelf-deep }}$ & & $5-100$ & This study \\
\hline$K_{\text {Oni }}$ & half-saturation uptake of $\mathrm{O}_{2}$ in nitrification & $283 \mathrm{nM}$ & B16 \\
\hline$K_{\mathrm{Nni}}$ & half-saturation uptake of $\mathrm{NH}_{4}^{+}$in nitrification & $100 \mu \mathrm{M}$ & F05 \\
\hline$K_{\mathrm{d}}$ & half-saturation uptake of $\mathrm{NO}_{3}^{-}$in denitrification & $8 \mu \mathrm{M}$ & \\
\hline$K_{\mathrm{NP}}$ & Redfield term & $8.47 \mu \mathrm{M}$ & G85, E13 \\
\hline$K_{\mathrm{N}}$ & half-saturation uptake of total $\mathrm{N}$ & $1.6 \mu \mathrm{M}$ & F05 \\
\hline$K_{\mathrm{P}}$ & half-saturation uptake of $\mathrm{PO}_{4}^{3-}$ & $0.1 \mu \mathrm{M}$ & F05 \\
\hline$K_{\mathrm{f}}$ & half-saturation uptake of $\mathrm{N}_{2}$ during fixing & $9.87 \times 10^{18} \mathrm{~mol}$ & K89 \\
\hline$K_{\mathrm{O}}$ & $\mathrm{O}_{2}$ concentration term & $50 \mu \mathrm{M}$ & \\
\hline \multirow[t]{2}{*}{$K_{\text {dist }}$} & percent of species extracted & 0.90 & \\
\hline & during MORB-genesis & & \\
\hline$\tau_{\text {prod }}$ & Export production time-scale & $0.5 \mathrm{yr}^{-1}$ & \\
\hline$\tau_{\mathrm{W}}$ & rate constant of weathering & $3.33 \times 10^{-9} \mathrm{yr}^{-1}$ & \\
\hline$\tau_{\mathrm{scg}}$ & rate constant of & $1 \times 10^{-8} \mathrm{yr}^{-1}$ & this study \\
\hline$\mu_{\mathrm{NH} 4 \mathrm{i}}$ & nitrification rate constant & $1 \mathrm{yr}^{-1}$ & F05 \\
\hline $\mathrm{O}_{\text {inhib }}$ & Oxygen inhibition for denitrification & $205 \mathrm{nM}$ & D14 \\
\hline$u_{c o}$ & Modern spreading rate & $0.05 \mathrm{~m} \mathrm{yr}^{-1}$ & K10 \\
\hline$T_{o}$ & Modern mantle potential temperature & $1350{ }^{\circ} \mathrm{C}$ & K10 \\
\hline$\rho_{c}$ & Ocean crust density & $3000 \mathrm{~kg} \mathrm{~m}^{-3}$ & \\
\hline$M^{\text {desed }}$ & mass of deep sediments & $7.3 \times 10^{23} \mathrm{~g}$ & JG15 \\
\hline$M^{\text {occrust }}$ & mass of ocean crust & $5.4 \times 10^{24} \mathrm{~g}$ & JG15 \\
\hline \multirow[t]{2}{*}{$M^{\text {mantle }}$} & mass of mantle & $4 \times 10^{27} \mathrm{~g}$ & JG15 \\
\hline & shelf sediments to cont. crust & & \\
\hline$a_{\mathrm{W}}$ & Anoxic weathering fraction & 0.1 & this study \\
\hline$k_{\text {weath }}$ & Weathering rate $\mathrm{O}_{2}$ dependence & $1 \times 10^{-3}$ & this study \\
\hline $\mathrm{V}_{\text {hydro }}$ & hydrothermal circulation volume & $1.6 \mathrm{~Sv}$ & this study \\
\hline Heff & Hydrothermal retention efficiency & $0.1-1$, varies by species & this study \\
\hline \multirow[t]{2}{*}{$P_{m}$} & percent partial melt & $10 \%$ & W01 \\
\hline & during MORB-genesis & & \\
\hline
\end{tabular}


Table 2 Model Constants - continued from previous page

\begin{tabular}{lrrc}
\hline Parameter & \multicolumn{1}{c}{ Definition } & Value & Reference \\
\hline$S$ & spreading rate $\left(\mathrm{m} \mathrm{yr}^{-1}\right)$ & varies & K10 \\
$h_{\text {sed }}$ & sediment thickness & $500 \mathrm{~m}$ & this study \\
$h_{c}$ & Ocean crust thickness & 16000 to $8000 \mathrm{~m}$ & $\mathrm{~K} 10$ \\
$L_{S}$ & length of subduction zones & $4 \times 10^{7} \mathrm{~m}$ & this study \\
$L_{r}$ & length of mid-ocean ridges & $8 \times 10^{7} \mathrm{~m}$ & this study \\
$f_{\text {shsed }}$ & fraction shelf sediments subducted & $1 \times 10^{-9}$ & this study \\
$f_{\mathrm{Ncgarc}}$ & fraction N added to continental crust & 0.5 & this study \\
\hline
\end{tabular}

\subsection{Geologic model}

The model is driven by a mantle cooling history from Korenaga [2010] and Padhi et al. [2012]. This model suggests that mantle temperatures $\left(T_{m}\right)$ increased through the early Archean, reached their peak in the middle Archean, and have been decreasing to the modern day (Table 3, Fig. 3). Heat flux $(Q)$ followed a distinct evolution, reaching its maximum later than the mantle temperature apex (Table 3). Temperature and heat flux are used to parameterize a plate velocity $\left(u_{c}\right)$ :

$$
u_{c}=u_{c o} \frac{Q}{Q o}\left(\frac{T_{o}}{T_{m}}\right)^{2}
$$

where $u_{c o}, Q_{o}$, and $T_{o}$ are modern plate velocity $\left(0.05 \mathrm{~m} \mathrm{yr}^{-1}\right)$, heat flux (39 TW), and average mantle temperature $\left(1350^{\circ} \mathrm{C}\right)$.

The model then calculates crust production at mid-ocean ridges by combining spreading rate with ridge length $\left(L_{r}, \mathrm{~m}\right)$ and crust thickness $\left(h_{c}, \mathrm{~m}\right)$ :

$$
O_{p}=u_{c} h_{c} L_{r} \rho_{c}
$$

where $\rho_{c}$ is crust density $\left(\mathrm{kg} \mathrm{m}^{-3}\right)$, and $h_{c}$ decreases linearly through time [Sleep and Windley, 1982] from $16 \mathrm{~km}$ at the beginning of the model to $8 \mathrm{~km}$ at $t=4.5 \mathrm{Gyr}$. We assume that the amount of crust subducted $\left(O_{s}\right)$ is equal to $O_{p}$. 
Table 3: Mantle temperature $\left(T_{m}\right)$ history, heat flux $(Q)$, and spreading rate $\left(u_{c}\right)$ evolution from Korenaga [2010]; Padhi et al. [2012].

\begin{tabular}{lccc}
\hline Age (Ga) & $T_{m}{ }^{\circ} \mathbf{C}$ & $Q(\mathbf{T W})$ & $u_{c}\left(\mathbf{c m ~ y r}^{-1}\right)$ \\
\hline 0 & 1350 & 39 & 5.00 \\
0.5 & 1425 & 43 & 5.55 \\
1.0 & 1490 & 41 & 4.68 \\
1.5 & 1540 & 40 & 4.22 \\
2.0 & 1600 & 39 & 3.75 \\
2.5 & 1680 & 38 & 3.28 \\
3.0 & 1700 & 37 & 3.05 \\
3.5 & 1700 & 37 & 3.05 \\
4.0 & 1670 & 37.5 & 3.23 \\
4.5 & 1650 & 38 & 3.38 \\
\hline
\end{tabular}

\subsection{Sediments}

Anything that does not get remineralized in the reactive sediment boxes gets buried $\left(F_{\text {bur }}^{i}\right)$ in sediments:

$$
F_{\text {bur }}^{i}=F_{\text {burial }}^{i *}-F_{\text {remin }}^{i *}
$$

for boxes $i=\{$ shelf sediments, deep sediments $\}$ and $i *=\{$ reactive shelf sediments, reactive deep sediments $\}$. Species are subducted from both deep and shelf sediments. A constant fraction of shelf sediment species gets subducted,:

$$
F_{\text {sub,j }}^{\text {shsed }}=f_{\text {shsed }} R_{j}^{\text {shsed }}
$$


where $f_{\text {shsed }}$ is the fraction of shelf sediments that subduct $\left(1 \times 10^{-9} \mathrm{yr}^{-1}\right)$. Deep sediments subducted are equal to:

$$
F_{\mathrm{sub}, \mathrm{j}}^{\mathrm{dsed}}=\frac{m_{\mathrm{sub}}^{\mathrm{dsed}} R_{j}^{\mathrm{dsed}}}{M^{\mathrm{dsed}}}
$$

where $m^{\text {desed }}$ is the mass of deep sediments subducted and $M^{\text {dsed }}$ is the mass of deep sediments $\left(7.4 \times 10^{23} \mathrm{~g}\right)$. Mass of sediments subducted is:

$$
m_{\mathrm{sub}}^{\mathrm{dsed}}=L_{\mathrm{s}} S h_{\text {sed }} \rho_{\mathrm{sed}}
$$

where $L_{S}$ is subduction zone length $(\mathrm{m}), S$ is spreading rate $\left(\mathrm{m} \mathrm{yr}^{-1}\right)$ calculated from Korenaga model, $h_{\text {sed }}$ is thickness of sediments $(500 \mathrm{~m})$, and $\rho_{\text {sed }}$ is sediment density $(2.5 \mathrm{~g}$ $\left.\mathrm{cm}^{-3}\right)$.

In addition, shelf sediments have a residence time of $100 \mathrm{Myr}$, or a rate constant of $\tau_{\text {scg }}=1 \times 10^{-8} \mathrm{yr}^{-1}$. Shelf sediments are added to the continental crust, representing a proxy for continental growth by collision and accretion:

$$
F_{\mathrm{scg}, \mathrm{j}}=\tau_{\mathrm{scg}} R_{j}^{\mathrm{shsed}}
$$

for $j=\{$ all species $\}$.

\subsection{Crust}

\subsubsection{Oceanic}

Species can enter the oceanic crust through hydrothermal alteration, and the leave the oceanic crust during subduction. We envision hydrothermal processes essentially as serpentinization, and overall it adds $\mathrm{N}$ to the oceanic lithosphere [Halama et al., 2014]. The amount of hydrothermal alteration is related to both speciation and a volume of hydrothermal fluid flow per year:

$$
F_{\text {hydro, } \mathrm{j}}=C_{j}^{\text {deep }} V_{\text {hydro }} H_{\text {eff }}
$$

for all model species. $H_{\text {eff }}$ is 1 for $\mathrm{K}$ and $\mathrm{NH}_{4}^{+}, 0.5$ for $\mathrm{NO}_{3}^{-}$and $\mathrm{PO}_{4}^{3-}$, and 0.01 for Ar. We set $V_{\text {hydro }}$ equal to 1.6 Sv [Elderfield and Schultz, 1996; German and Seyfried, 2014] for nominal runs, but allowed it to vary during sensitivity tests. 
The subduction flux is calculated by multiplying the mass of crust subducted per year by each species concentration in the crust:

$$
F_{\mathrm{sub}, j}^{\mathrm{oc}}=\frac{R_{j}^{\text {ocrust }} O_{p}}{M^{\text {occrust }}}
$$

where $O_{p}$ is ocean crust produced and $M_{\text {occrust }}$ is the total mass of crust (g).

Thus, the total amount of each species subducted $\left(F_{\text {subT }}\right)$ is

$$
F_{\mathrm{subT}, j}=F_{\mathrm{sub}, j}^{\mathrm{oc}}+F_{\mathrm{sub}, j}^{\mathrm{dsed}}+F_{\mathrm{sub}, j}^{\mathrm{shsed}}
$$

Subducted species will either be driven off the slab and sediments or carried beyond the subduction barrier and into the mantle. The proportion that is driven off the slab is determined by mantle temperature: higher temperature means less material goes into the mantle, and lower temperature means more material goes into the mantle. Subducted fraction is calculated from an average geothermal gradient $\left(G_{\text {sub }}\right.$ in $\left.{ }^{\circ} \mathrm{C} \mathrm{km}^{-1}\right)$, which in turn is calculated from an average mantle temperature $\left(T_{m}\right)$ :

$$
G_{\text {sub }}=\frac{12.2\left(T_{m}-273\right)}{2900}
$$

where $T_{m}$ is in kelvin, 2900 is mantle depth in $\mathrm{km}$, and 12.2 is a conversion factor to adjust average mantle temperature, consistent with the modern average mantle geothermal gradient. Subducted fraction is a hyperbolic tangent fit to the data from modern geothermal gradients and subducted fluxes at three modern subduction zones [Elkins et al., 2006; Mitchell et al., 2010; Zelenski et al., 2012], and can vary between 0.1 and 1:

$$
f_{\text {sub }}=0.5\left(1.1-0.9 \tanh \left(\frac{G_{\text {sub }}-6}{0.6}\right)\right)
$$

The values inside the tanh parenthetical, 6 and 0.6 , have units of ${ }^{\circ} \mathrm{C} \mathrm{km}^{-1}$. We again note previous work that has indicated there is likely more complication in the ratio between $\mathrm{N}$ that is subducted at the trench and that which is sequestered to the mantle. While temperature is assumed to have a first-order effect in our model, redox [Libourel et al., 2003; Li et al., 2016], pH [Mikhail and Sverjensky, 2014], and distribution between fluids and melt [Li et al., 2015; Mallik et al., 2018], may all have effects which are not considered here.

Thus, the flux of species subducted to the mantle is the product of subducted fraction, concentration in sediments or crust, and mass of sediments/crust subducted per year: 


$$
F_{\text {subnet }, \mathrm{j}}=f_{\text {sub }} F_{\text {subT,j }} \text {. }
$$

for $j=\{$ all species $\}$.

\subsubsection{Continental}

That which is not subducted will either be outgassed at arcs $\left(F_{\text {ogarc }}\right)$ or be incorporated into the continental crust $\left(F_{\mathrm{cg}}\right)$. All Ar is outgassed, all $\mathrm{K}$ and $\mathrm{PO}_{4}^{3-}$ goes into the continental crust. For $\mathrm{N}, f_{\mathrm{Ncgarc}}$ is set to 0.5 . That is, half of $\mathrm{N}$ released from subducted materials is outgassed at arcs and half is incorporated into the continental crust. This value, 0.5 , is an assumption in our model. There is very little data concerning $\mathrm{N}$ in subduction zones that is released from the slab. Nitrogen isotopes in granites indicate a biologic source [Boyd, 2001; Johnson and Goldblatt, 2017], which could be from subducted material. More analysis of granitic rocks would help characterize this flux. Thus:

$$
F_{\mathrm{cg}, j}=\left(1-f_{\mathrm{sub}}\right) F_{\mathrm{subT}, \mathrm{j}}
$$

for $j=\left\{\mathrm{K},{ }^{40} \mathrm{~K},{ }^{40} \mathrm{Ar},{ }^{36} \mathrm{Ar}\right\}$ and

$$
F_{\mathrm{cg}, \mathrm{N}}=f_{\mathrm{Ncgarc}}\left(1-f_{\text {sub }}\right) F_{\text {subT, } \mathrm{N}}
$$

for $\mathrm{N}$. All subducted $\mathrm{PO}_{4}^{3-}$ is added to the continental crust.

Species in the continental crust have a residence time of $300 \mathrm{Myr}$, or time constant $\left(\tau_{w}\right)$ of $3.33 \times 10^{-9} \mathrm{yr}^{-1}$, which is equivalent to half a Wilson cycle [Nance and Murphy, 2013]. Weathering efficiency depends on atmospheric $\mathrm{O}_{2}$, with weathering increasing with increasing $\mathrm{O}_{2}$ :

$$
W_{\mathrm{eff}, j}=\tau_{\mathrm{w}}\left(a_{\mathrm{W}}+\left(1-a_{\mathrm{W}}\right) \frac{P A L_{\mathrm{O} 2}}{P A L_{\mathrm{O} 2}+k_{\mathrm{weath}}}\right)
$$

Where $a_{\mathrm{W}}$ is the fraction of available material weathered under anoxic conditions $(0.1)$, $P A L_{\mathrm{O} 2}$ is atmospheric $\mathrm{O}_{2}$ compared to present atmospheric levels, and $k_{\text {weath }}$ is a weathering rate constant $\left(1 \times 10^{-3}\right)$. Weathered ${ }^{36} \mathrm{Ar}$ and ${ }^{40} \mathrm{Ar}$ are released to the atmosphere, while all other species $\left(\mathrm{N}, \mathrm{PO}_{4}^{3-}, \mathrm{K}\right)$ are added to the shelf ocean. As there is no crustal organic 
material in the model, all continental $\mathrm{N}$ is weathered as $\mathrm{NH}_{4}^{+}$, which is the mineralogically most stable form of $\mathrm{N}$. Weathering $\left(F_{\mathrm{W}}\right)$ is parameterized as:

$$
F_{\mathrm{w}, j}=W_{\mathrm{eff}} R_{j}^{\text {contcrust }}
$$

\subsection{Mantle}

Species are added to the mantle at subduction zones $\left(F_{\text {subnet }}\right)$. It is assumed that they instantly homogenize into the mantle (i.e., there are no separate mantle domains). Species leave the mantle through degassing at mid-ocean ridges. Degassing is the product of the concentration $\left(C_{j}^{\operatorname{man}}\right)$ of the species in the mantle and the mass of mantle involved in crust genesis $\left(M_{\text {melt }}\right) . M_{\text {melt }}$ is set to 10 times the mass of oceanic crust produced $\left(O_{p}\right)$, which and represents generation of crust by $10 \%$ partial melt $\left(P_{m}\right)$. We assume $90 \%$ of all species are partitioned to the melt during partial melting $\left(K_{\text {dist }}\right)$, with $10 \%$ remaining in the residual. We have chosen this partition of melt to residual to account for the observation that mantle rocks that have undergone some melting still have low, but measurable $\mathrm{N}$ of less than $1 \mathrm{ppm}$ [Johnson and Goldblatt, 2015, and references therein]. Thus, midocean ridge outgassing is:

$$
F_{\mathrm{ogmor}, j}=C_{j}^{\operatorname{man}} P_{m} O_{p} K_{\mathrm{dist}} .
$$

We note that there is no explicit treatment of intra-plate, or hot spot, volcanism in the model. In addition, we do not distinguish between the upper mantle, transition zone, and lower mantle. There are redox changes with depth in the mantle [e.g. Frost and McCammon, 2008], which have important effects on $\mathrm{N}$ solubility in mantle minerals [Li et al., 2013, 2016]. As discussed in Li et al. [2013] and Johnson and Goldblatt [2015], the mantle likely has an enormous capacity for $\mathrm{N}$, which likely exceeds its actual content at any given time. Future modeling work including mantle structure and redox evolution would be an important addition to the work shown herein.

\subsection{Details on code structure}

The model code was constructed to prioritize flexibility. Due to the high number of unknowns in the system, giving flexibility was important. We set up the reservoir book- 
keeping as a structure array in Matlab. This allows for dynamic field names to be used, which assists in ease of code reading. We also constructed it so that initial conditions are read in through a separate text file. This allows easy changes, but it is also flexible as not every species has to be in every box. It also calculates ${ }^{40} \mathrm{~K}$ from $\mathrm{K}$ initial conditions, reducing input time and error.

The differential equation file is arranged so that it is straightforward to turn various fluxes off and on. The purpose for this design is that this model, or one like it, could be used for not only Earth history, but could be applied to planetary evolution in general. Different planetary evolution pathways may or may not involve subduction, different atmospheric compositions, or differing biologic pathways and metabolisms. Testing the response of the system to such differences, perturbations, and the presence or absence of one or more fluxes could be of great value in studying planetary evolution.

In detail, we used Matlab's ode15s solver. This is a variable-step, variable-order solver that uses numerical differentiation formulas of orders 1 to 5 . We set the relative error tolerance to $1 \times 10^{-7}$ and a maximum step size of $10^{6}$ years. Code is available in the supplementary material. Please contact us if you wish to use this code in order to obtain the latest version.

\section{Results and Discussion}

We ran the model in all runs for $4.5 \mathrm{Ga}$, after a spin up period of $10 \mathrm{Myr}$ to equilibrate atmosphere, ocean, and sediment boxes. All biologic N fluxes are "available" at each model step.

\subsection{Nominal Run}

In order to test the effects of different conditions over Earth history, such as oxygenic photosynthesis evolution time and style of mantle cooling, we first describe the results of a nominal model run.

This realization is based on a conservative set of assumptions regarding initial and boundary conditions and choice of parameterizations (Fig. 3). Mantle cooling and midocean ridge crust production (i.e., mid-ocean ridge outgassing) is from Korenaga [2010], with the fraction of subducted $\mathrm{N}$ retained to the deep mantle dependent on mantle temperature. The atmospheric $\mathrm{O}_{2}$ history is prescribed, and oxygenic photosynthesis evolves at 
2.8 Ga. Plate tectonics starts at $3.5 \mathrm{Ga}$, continental weathering timescale is $300 \mathrm{Myr}$, and hydrothermal alteration is parameterized as a fixed volume flow (1.6 Sv).

We estimate the proportions of $\mathrm{N}$ that start in the atmosphere and the mantle at the end of the magma ocean phase of Earth history, and use this as the initial condition for the nominal run (Appendix B: ). Using results from Libourel et al. [2003], which relates $\mathrm{pN}_{2}$ to $\mathrm{N}$ dissolved in basaltic magma, and a mantle $f \mathrm{O}_{2}$ of IW-2 [Wood et al., 2006], which is expected at the end of core formation, we calculate $\mathrm{N}_{2}$ concentration in a magma ocean for a range of atmospheric $\mathrm{pN}_{2}$ values. We assume the entire mantle experienced a magma ocean phase. Then, given this relationship, we can estimate a total $\mathrm{N}$ budget and what proportion of that $\mathrm{N}$ starts in the atmosphere and the mantle. We select a total $\mathrm{N}$ budget for the nominal run to be consistent with budget estimates from Johnson and Goldblatt [2015], and one that reproduces the current distribution of $\mathrm{N}$ in the atmosphere (1 PAN) and the mantle (>3 PAN). Our starting conditions are therefore total $\mathrm{N}$ of 4.8 PAN, with $80 \%$ starting in the atmosphere and $20 \%$ in the mantle. The evolution of major $\mathrm{N}$ reservoirs (atmosphere, mantle, continental crust, ocean sediments) is shown in Fig. 4 with atmosphere-ocean gases and nutrients shown in Fig. 5.

Table 4: Nitrogen reservoir and flux comparisons: nominal model output results compared to literature N mass estimates from Johnson and Goldblatt [2015], with continental crust from Johnson and Goldblatt [2017]. Reservoirs are in units of $10^{18} \mathrm{~kg} \mathrm{~N}$, while ocean concentrations are shown in $\mu \mathrm{M}$. Shallow ocean model results are the average of low-latitude, high-latitude, and shelf boxes. Deep ocean values from the literature are for $1000 \mathrm{~m}$ depths. Model values are from the end of nominal model run (i.e., modern values). Fluxes are in $\mathrm{Tmol} \mathrm{N} \mathrm{yr}^{-1}$ unless otherwise noted. Model results are shown for modern day reservoir fluxes.

\begin{tabular}{lccl}
\hline Reservoir/Flux & Model & Literature & Reference \\
\hline Atmosphere & 3.92 & 4 & Johnson and Goldblatt [2015] \\
Mantle & 12 & $24 \pm 16$ & Johnson and Goldblatt [2015] \\
Continental Crust & 1.8 & $1.7-2.7$ & Johnson and Goldblatt [2015, 2017] \\
Oceanic Lithosphere & 0.05 & $0.2 \pm 0.02$ & Johnson and Goldblatt [2015] \\
Total ocean Sediments & 1.2 & $0.41 \pm 0.2$ & Johnson and Goldblatt [2015] \\
Shallow ocean $\mathrm{NO}_{3}^{-}$ & 22 & 7 & Gruber [2008] \\
\hline
\end{tabular}


Table 4 Reservoir comparison - continued from previous page

\begin{tabular}{|c|c|c|c|}
\hline Reservoir/Flux & Model & Literature & Reference \\
\hline Deep ocean $\mathrm{NO}_{3}^{-}$ & 25 & 31 & Gruber [2008] \\
\hline Shallow ocean $\mathrm{NH}_{4}^{+}$ & 2.4 & 0.3 & Gruber [2008] \\
\hline Deep ocean $\mathrm{NH}_{4}^{+}$ & 1.5 & 0.01 & Gruber [2008] \\
\hline Shallow ocean $\mathrm{PO}_{4}^{3-}$ & 0.12 & $<1$ & Garcia et al. [2014] \\
\hline Deep ocean $\mathrm{PO}_{4}^{3-}$ & 0.36 & $1-3$ & Garcia et al. [2014] \\
\hline Shallow ocean $\mathrm{O}_{2}$ & 533 & $220-400$ & Garcia et al. [2014] \\
\hline Deep ocean $\mathrm{O}_{2}$ & 530 & $40-400$ & Garcia et al. [2014] \\
\hline \multicolumn{4}{|l|}{ Biologic fluxes } \\
\hline N-fixing & 6.4 & 13 & Gruber and Galloway [2008]; Vitousek et al. [2013] \\
\hline Nitrification & 19 & 85 & Gruber [2008] \\
\hline Denitrification & 6 & 22 & Gruber [2008] \\
\hline N-remineralization & 21 & 93 & Gruber [2008] \\
\hline \multicolumn{4}{|l|}{ Geologic Fluxes } \\
\hline Continental weathering & 0.43 & 1.1 & Houlton et al. [2018] \\
\hline Burial/sedimentation & 0.73 & 0.07 & Gruber [2008] \\
\hline \multirow[t]{3}{*}{ Total subduction } & 0.66 & 0.0064 & Mallik et al. [2018] \\
\hline & & 0.0094 & Busigny et al. [2011] \\
\hline & & 0.1 & Halama et al. [2014] \\
\hline Arc outgassing & 0.08 & 0.0375 & Catling and Kasting [2017] \\
\hline Mid-ocean ridge outgassing & 0.2 & 0.0038 & Catling and Kasting [2017] \\
\hline Total outgassing & 0.28 & 0.09 & Catling and Kasting [2017] \\
\hline
\end{tabular}

We focus first on model output at the modern day. The nominal run reproduces the modern atmospheric and estimated mantle $\mathrm{N}$ masses well. The mantle value, specifically, is somewhat lower, but within the estimated mantle $\mathrm{N}$ budget from Johnson and Goldblatt [2015], which is $7 \pm 4$ PAN. The nominal run has 3.25 PAN in the mantle at modern. We present full comparisons with values from the literature in Table 4. 
Model output is consistent with estimates for the modern day $\mathrm{N}$ budget in deep sediments of $~ 0.1$ PAN [Johnson and Goldblatt, 2015], and continental crust. For example, recent work using glacial tills as a proxy for upper continental crust through time suggest a secular increase in crustal $\mathrm{N}$ during the Precambrian [Johnson and Goldblatt, 2017]. The authors suggest that isotopic evidence is most consistent with this addition of $\mathrm{N}$ to the continents being biological in origin. Atmospheric $\mathrm{N}$ is biologically fixed and then subsequently added to the continents either via collision of marginal marine sediments or incorporation from subduction zone processing, with a total crust $\mathrm{N}$ content of $0.5-0.67$ PAN. While we do have both of these fluxes in our model, they are only very general. It is well known that the Earth has gone through periods of orogenic activity and periods of quiescence [e.g., Condie, 2013] with variable passive margin extent [Bradley, 2008], and these variations are not captured in our model.

In all model runs, prior to the evolution of oxygenic photosynthesis the $\mathrm{N}$ cycle is marked by mantle degassing and atmospheric $\mathrm{N}$ growth, after a period of atmospheric equilibration with oceanic sediments. (Figs. 4 - 6). High mantle temperatures, combined with low efficiency export production and $\mathrm{N}$-fixing results in net mantle outgassing and atmospheric growth for the first $1.5 \mathrm{Ga}$ of model output. Biologic $\mathrm{N}$ fluxes (Fig. 7) are low prior to oxygenic photosynthesis, due to lower overall productivity and burial. Then, coincident with, and caused by, the appearance of oxygenic photosynthesis, the atmosphere is drawn down, with an increase in all the geologic $\mathrm{N}$ reservoirs. Deep ocean sediments increase most quickly, with continental crust and the mantle increasing more slowly. At the GOE, an increase in weathering drives a spike in productivity and further atmospheric draw-down due to enhanced $\mathrm{N}$-fixing. The Lomagundi-Jatuli type event, with high productivity, lasts for $\sim 50 \mathrm{Myr}$. At about $1.6 \mathrm{Ga}$, the mantle and atmosphere have equal $\mathrm{N}$ budgets, and the mantle continues to increase at the expense of all other reservoirs until the present day.

While the nominal run reproduces modern $\mathrm{N}$ distribution well, there are discrepancies between modeled biologic and geologic fluxes and estimates of these fluxes from the literature (Fig. 4). The model somewhat underestimates N-fixing, nitrification, and denitrification. It is possible to explain some of this discrepancy by the lack of continental biologic N-cycling in our model, since at present continental ecosystems account for half of global biologic N cycling [e.g., Gruber and Galloway, 2008]. Similarly, nominal output for 

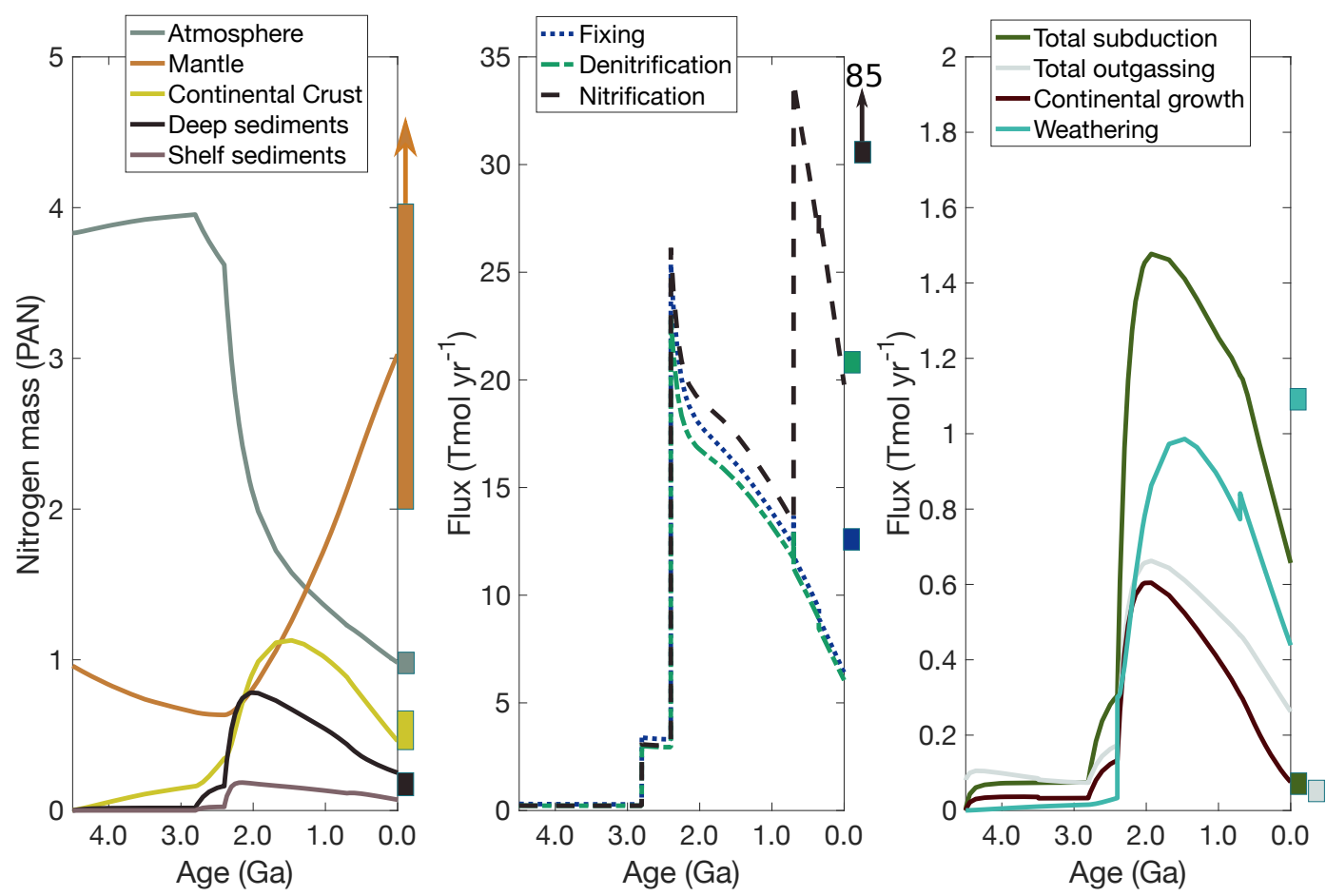

Figure 4: a. Nitrogen reservoirs through time from a nominal run. b. Biologic nitrogen fluxes and c. Geologic fluxes. Estimates for modern amounts are shown as colored bars next to each panel [Gruber, 2008; Gruber and Galloway, 2008; Busigny et al., 2011; Vitousek et al., 2013; Halama et al., 2014; Johnson and Goldblatt, 2015; Catling and Kasting, 2017; Mallik et al., 2018; Houlton et al., 2018].

continental $\mathrm{N}$ weathering is less than a recent study [Houlton et al., 2018]. Adding more explicit treatment of continental $\mathrm{N}$ cycling would be a welcome addition to this model.

For the other major geologic fluxes, outgassing and subduction, the EarthN model output is higher than estimates from the literature. This indicates that either subduction of $\mathrm{N}$ is not as efficient as we describe, and recycling into the mantle is less, or literature estimates of subduction and outgassing are too low. It is notoriously difficult to estimate $\mathrm{N}$ fluxes outgassing at subduction zones and mid-ocean ridges [Fischer et al., 2002; Elkins et al., 2006], due to high background atmospheric $\mathrm{N}_{2}$. In addition, there are very few estimates of N cycling in subduction zones [Fischer et al., 2002; Elkins et al., 2006; Mitchell et al., 2010; Halama et al., 2014; Mallik et al., 2018], and it is possible that this flux is being underestimated in the literature due to the difficulty in analyzing silicate-bound $\mathrm{N}$. 


\subsubsection{Ocean nutrients through time}

Our results yield several important predictions of nutrient content of the ocean through time. First, and unsurprisingly, $\mathrm{NH}_{4}^{+}$is the dominant bioavailable $\mathrm{N}$ species in the ocean, and $\mathrm{PO}_{4}^{3-}$ remains high $(\sim 1-3 \mu \mathrm{M})$ before oxygenic photosynthesis. Second, after the appearance of oxygenic photosynthesis and the associated increase in productivity (Fig. 3), burial increases. The increase in burial is reflected in the increase in $\mathrm{N}$ in ocean sediments and in all biologic $\mathrm{N}$ fluxes (Fig. 4). We note here that since we do not include abiotic Nfixing, and instead assume biologic $\mathrm{N}$-fixing could operate throughout the model run, we might be slightly overestimating early Archean $\mathrm{N}$-fixing if biologic fixing did not evolve till 3.2 Ga [Stüeken et al., 2015]. For example, Navarro-González et al. [2001] suggests $2.1 \times 10^{10} \mathrm{~mol} \mathrm{yr}^{-1}$ could be fixed abiotically by lightning, while the minimum $\mathrm{N}$-fixing we calculate is $2.9 \times 10^{11} \mathrm{~mol} \mathrm{yr}^{-1}$. At the same time as the increase in $\mathrm{N}$-cycle fluxes, $\mathrm{PO}_{4}^{3-}$ concentrations drop an order of magnitude, again the result of increased productivity and burial. We also note that there is a small oxygen oasis in the shelf ocean box, which is consistent with evidence for localized oxic conditions prior to widespread oxygenation at the GOE [Anbar et al., 2007] Additionally, nutrient concentrations increase after the GOE, as the result of increased weathering efficiency.

Third, $\mathrm{NH}_{4}^{+}$and $\mathrm{NO}_{3}^{-}$are at about the same concentration in the Proterozoic. This balance is the result of $\mathrm{O}_{2}$ levels, and so is dependent on our $\mathrm{O}_{2}$ forcing scheme, which sets Proterozoic $\mathrm{O}_{2}$ levels at $1 \%$ of modern. There is not agreement on the exact level of $\mathrm{O}_{2}$ in the Proterozoic [Lyons et al., 2014; Planavsky et al., 2014; Reinhard et al., 2016; Zhang et al., 2016], but generally the maximum estimates are no greater than $10 \%$ of modern. Thus, the transition to a $\mathrm{NO}_{3}^{-}$-rich ocean is predicted to only occur at the NOE, and our modeling does not indicate any sort of N-limitation during the Proterozoic. We do not, however, model a specific increase in productivity due to the evolution of eukaryotes, which might be expected to enhance biologic N-cycling [e.g., Zerkle and Mikhail, 2017, and references therein].

\subsubsection{Different plate tectonic histories}

Different mantle cooling history could have a large effect on the transfer and sequestration of $\mathrm{N}$ from the surface into the mantle over time. For example, if mantle temperatures were hotter in the Archean, one might expect both faster mantle convection and less 


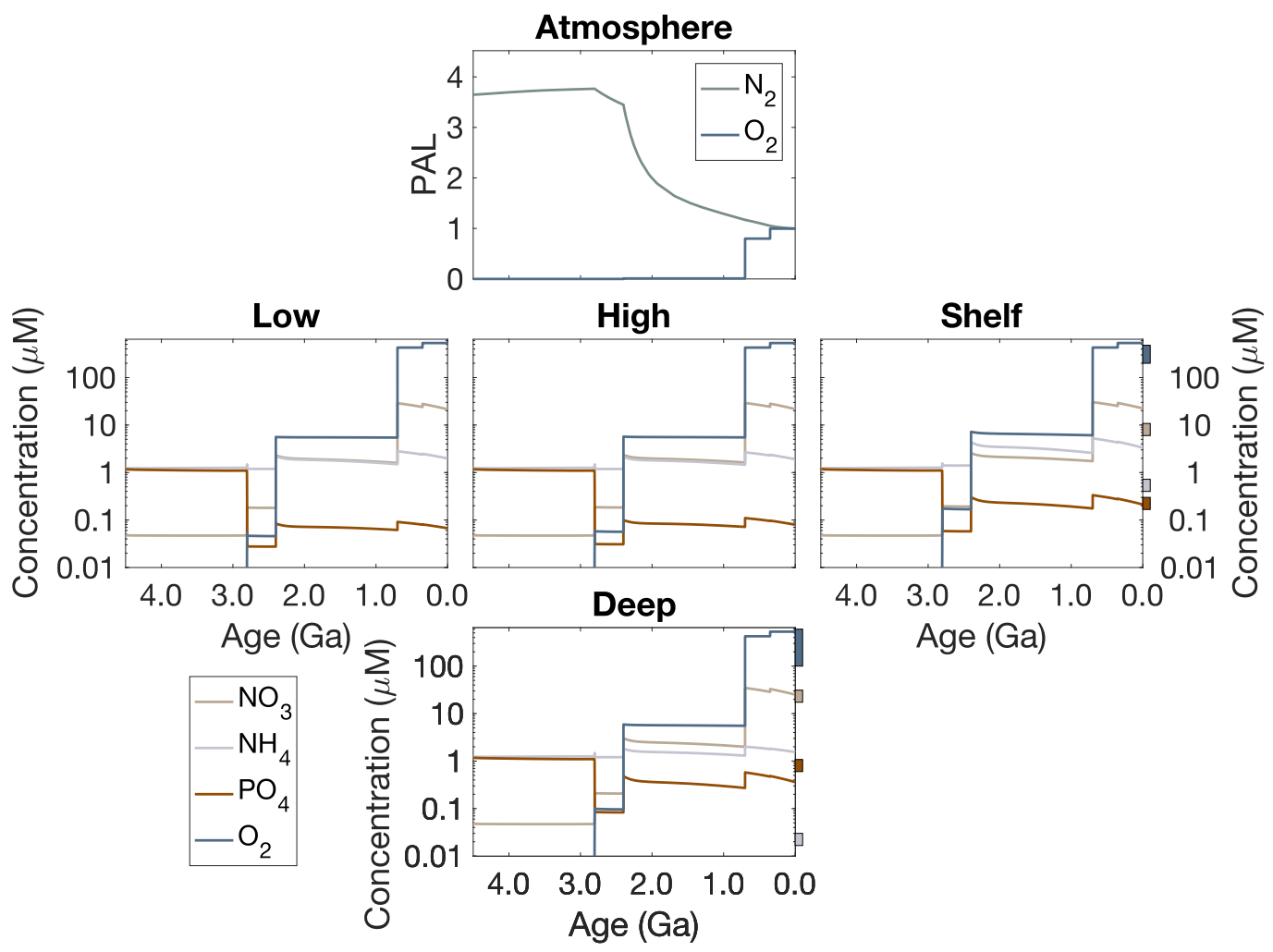

Figure 5: Nitrogen, $\mathrm{O}_{2}$, and $\mathrm{PO}_{4}^{3-}$ surface reservoirs through time for a nominal run. $\mathrm{NH}_{4}^{+}$is the dominant $\mathrm{N}$ species until the Neoproterozoic Oxygen Event, and $\mathrm{PO}_{4}^{3-}$ is high until the evolution of oxygenic photosynthesis. A small $\mathrm{O}_{2}$ oasis exists in the late Archean shelf ocean. Literature estimates for modern values are shown as colored bars next to shallow boxes; the shallow ocean bars are for the average shallow ocean, and deep ocean represents $1000 \mathrm{~m}$ depth [Gruber, 2008; Garcia et al., 2014].

efficient retention of $\mathrm{N}$ at subduction zones. Relatedly, if mantle temperature is not the main control on $\mathrm{N}$ retention into the mantle at subduction zones, different subduction efficiencies would lead to correspondingly different $\mathrm{N}$ histories.

To test these possibilities, we ran the model with three different styles of mantle cooling/plate tectonic transfer of $\mathrm{N}$ from the surface to the mantle (Fig. 6). The first, as described in the nominal run section, is based on Korenaga [2010]. In the second, mantle temperature, ocean crust production, and subducted crust are all constant, set to the average of each value from Sandu et al. [2011], which uses a "canonical" mantle cooling. In 
addition, the fraction of subducted $\mathrm{N}$ that is transported to the deep mantle is held constant at 0.2 . In the third realization, we allow subducted fraction to vary with canonical mantle evolution temperature.

In all three realizations, prior to oxygenic photosynthesis, there is net mantle outgassing and atmospheric growth. Similarly, after oxygenic photosynthesis and more efficient export production, there is net atmospheric drawdown into geologic reservoirs. The amount of drawdown by subduction with canonical mantle cooling, with either constant or temperature-linked efficiency, is more overall than in the nominal run, up to 4 PAN in the latter. Constant subduction efficiency, however, cannot sequester enough atmospheric $\mathrm{N}$ into the mantle to result in a 1 PAN atmosphere at modern. In addition, this run results in more $\mathrm{N}$ in the atmosphere than the mantle, contradicting estimates of $\mathrm{N}$ distribution on Earth today [Johnson and Goldblatt, 2015]. Interestingly, the overall pattern is insensitive to mantle cooling history.

We also explored realizations where the time of plate tectonic initiation and oxygenic photosynthesis were varied (Fig. 7). The initiation of plate tectonics does not affect the overall pattern, nor does it greatly effect the distribution of $\mathrm{N}$ between various reservoirs. Mantle cooling, and its effect on subduction efficiency, has a larger effect than timing of plate initiation alone. Similarly, only when biologic productivity increases after oxygenic photosynthesis do major changes in $\mathrm{N}$ distribution occur.

\subsubsection{Different oxygenic photosynthesis appearance}

Another main "knob" on the control panel of the $\mathrm{N}$ cycle is how biologic activity processes this in the oceans. As seen in the nominal run, the appearance of oxygenic photosynthesis and the GOE exert a large control over how active $\mathrm{N}$-fixing, nitrification, and denitrification are. To test for any effects of different times of oxygenic photosynthesis evolution (Fig. (Fig. 7), we ran the model with standard conditions, but altered when oxygenic photosynthesis evolves: early ( $3.5 \mathrm{Ga})$, middle $(2.8 \mathrm{Ga}$, standard), and late (2.4 $\mathrm{Ga}$ ). These times were chosen to coincide with early fossil evidence for photosynthetic life [Hofmann et al., 1999], molecular and geochemical evidence for oxygenic photosynthesis by $2.8 \mathrm{Ga}$ [see Buick, 2008], and the GOE at $2.4 \mathrm{Ga}$ [Farquhar et al., 2000].

In all runs, when oxygenic photosynthesis evolves, atmospheric $\mathrm{N}$ is drawn down. Initially, $\mathrm{N}$ is sequestered into deep sediments, then, if plate tectonics is operating, sent 

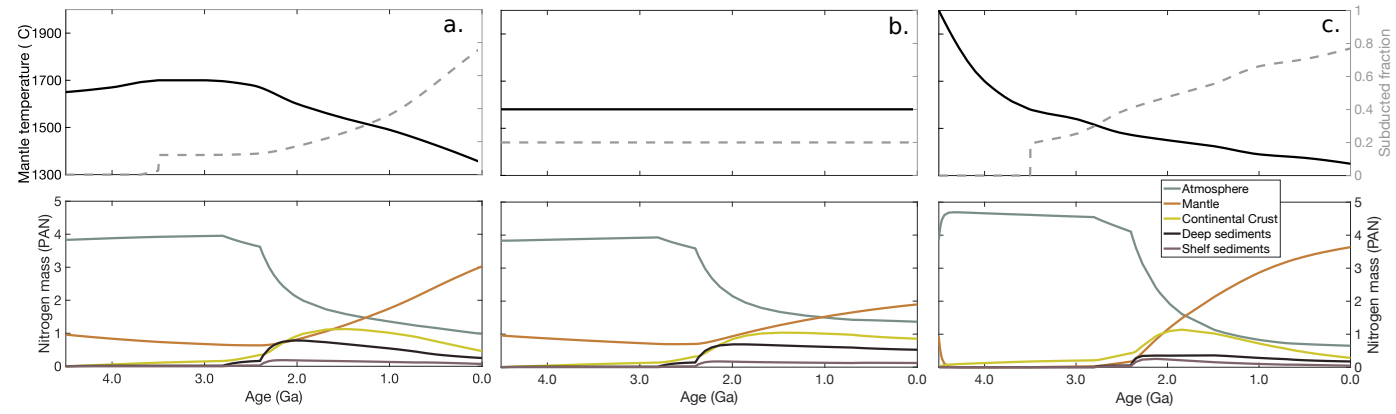

Figure 6: Nitrogen reservoirs and subducted fraction for different subduction parameters. a.) nominal run, b.) constant subduction, c.) canonical subduction. The Archean in all cases is characterized by net mantle outgassing, but outgassing is rapid in canonical subduction runs. Net drawdown occurs after oxygenic photosynthesis evolves, and deep sediments and continental crust increases as well.

into the mantle and continental crust. If oxygenic photosynthesis appears later, atmospheric $\mathrm{N}$ reservoir reaches a slightly higher maximum prior to drawdown. In addition, all else being equal, a later appearance of oxygenic photosynthesis results in a slightly higher $\mathrm{pN}_{2}$ at modern. Overall, the main change in N-history occurs at the GOE, driven by increased weathering, nutrient supply, and enhanced biologic productivity.

\subsection{Atmospheric $\mathrm{pN}_{2}$ comparison with other reconstructions}

As mentioned in the introduction, there is a discord between modern geochecmical data suggesting net ingassing of the atmosphere through time [Busigny et al., 2011; Nishizawa et al., 2007; Barry and Hilton, 2016] and either net outgassing [Som et al., 2012, 2016] or atmospheric stability since the Archean [Marty et al., 2013]. Our model strongly suggests dynamic behavior over time, with the $\mathrm{N}$ distribution on Earth responding to changes in biologic and geologic evolution over time.

In order to match constraints for similar or lower atmospheric $\mathrm{N}$ mass in the past [Marty et al., 2013; Som et al., 2012, 2016], but still end up with a 1 PAN modern atmosphere, our model has to be tuned to very specific parameters (Fig. 8) within an otherwise nominal run. Given our standard total $\mathrm{N}$ budget (4.8 PAN), the mantle must start with the majority (90\%) of total $\mathrm{N}$, due to net outgassing during the Hadean and Archean. In addition, the net subduction of $\mathrm{N}$ at subduction zones has to be low and constant (10\%), as an 

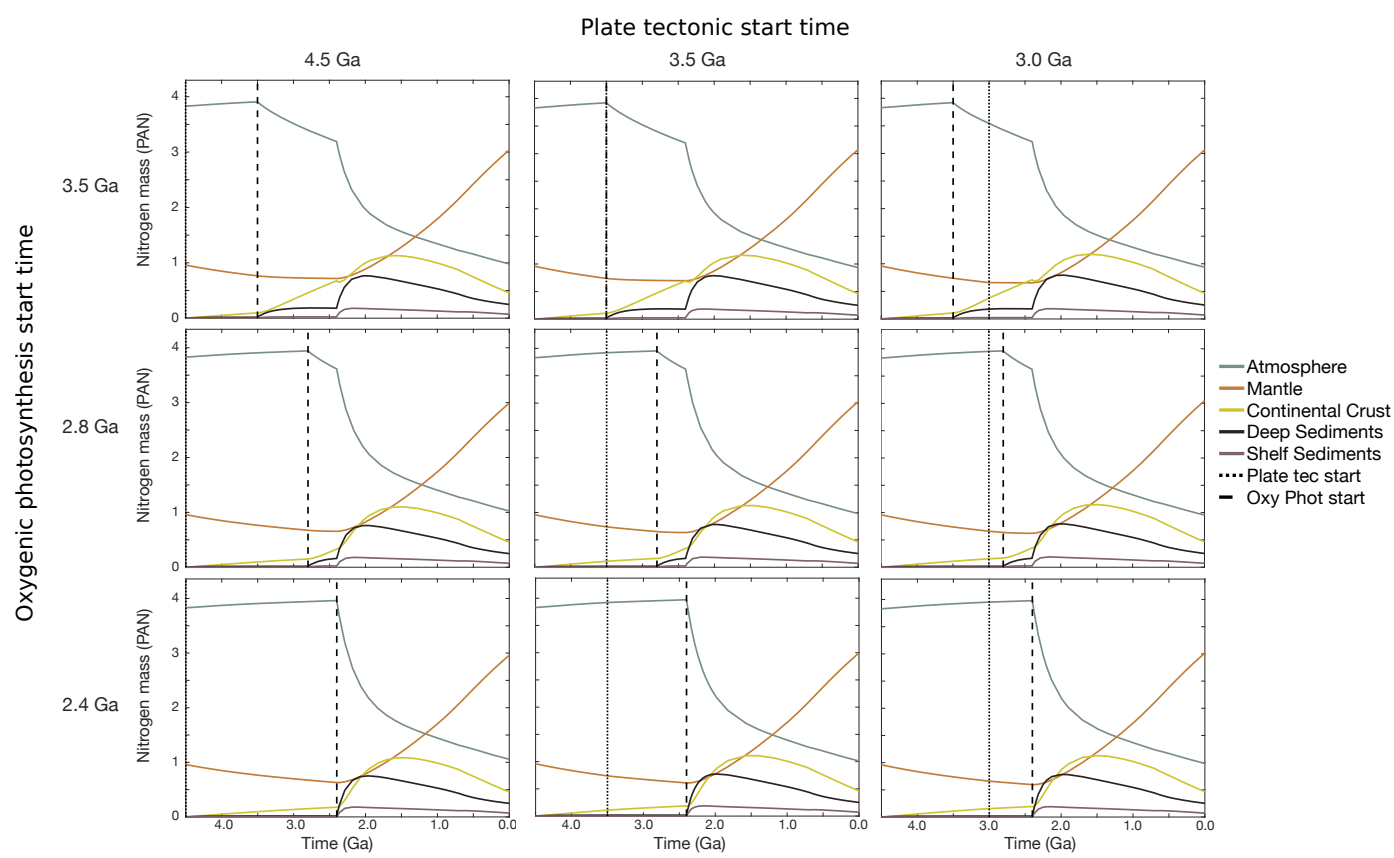

Figure 7: Nominal runs varying plate tectonic $(4.5,3.5,3.0 \mathrm{Ga})$ and oxygenic photosynthesis starting time $(3.5,2.8,2.4 \mathrm{Ga})$. The overall pattern for major $\mathrm{N}$ reservoirs is similar for all cases. Mantle $\mathrm{N}$ increases when subduction begins, atmospheric drawdown of $\mathrm{N}$ into ocean sediments occurs when oxygenic photosynthesis evolves, and further drawdown occurs after the GOE.

increase in net subduction over time results in atmospheric drawdown in all model runs. We also have to increase hydrothermal circulation from 5 to $50 \mathrm{~Sv}$, which limits $\mathrm{PO}_{4}^{3-}$ and in turn limits atmospheric drawdown via $\mathrm{N}$-fixing. The model with these parameters can reproduce the constraints of 1 PAN at 3.46 Ga [Marty et al., 2013] and a 0.5 PAN atmosphere at $2.7 \mathrm{Ga}$ [Som et al., 2012, 2016] but still result in a 1 PAN modern atmosphere. Even in this case, there is still a 1.75 PAN atmosphere at $2.8 \mathrm{Ga}$, when oxygenic photosynthesis evolves. The atmosphere undergoes a dynamic evolution.

Lower atmospheric mass in the past cannot be specifically ruled out by our model output, but such lower mass would present a number of interesting implications. The lack of evidence for large glaciations in the Archean is difficult to reconcile with low atmospheric mass [Goldblatt et al., 2009]. Similarly, the majority of the Proterozoic, or "boring billion", lacks evidence for glaciation, implying warm climate. If the Earth had less than a one PAN atmosphere, there would need to be $10^{-2.2}$ bars of $\mathrm{CO}_{2}$, and even more with less N. 

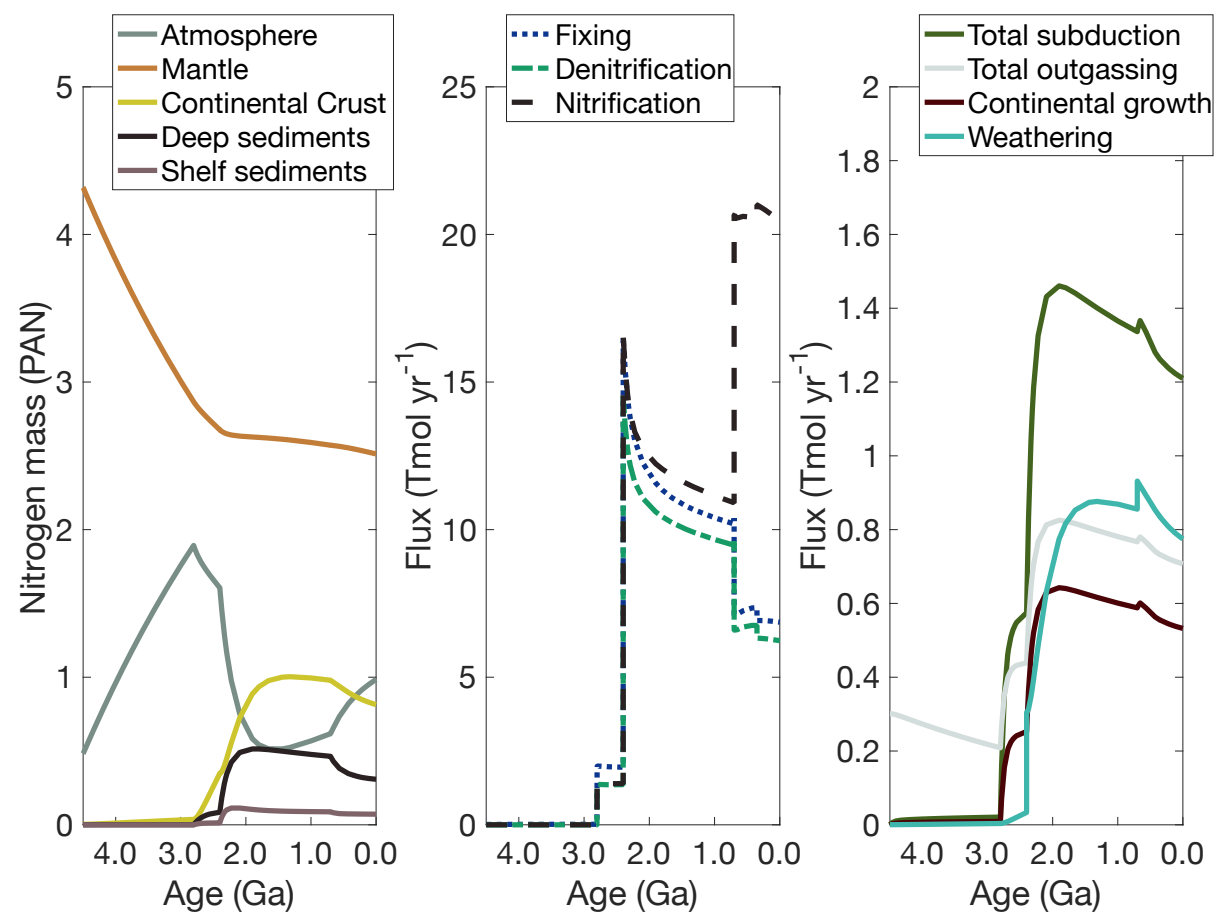

Figure 8: Nominal run but with low starting atmospheric mass, 5\% starting $\mathrm{N}$ in the atmosphere, constant net subduction (10\%), and high (50 Sv) hydrothermal circulation. These conditions lead to a model realization consistent with previous estimates of a 1 PAN atmosphere at $3.46 \mathrm{Ga}$ [Marty et al., 2013] and 0.5 PAN at $2.7 \mathrm{Ga}$ [Som et al., 2012, 2016]. 


\subsection{Investigating unknown nitrogen distribution: Monte Carlo simulations}

Despite recent interest in geologic and Earth system N cycling [Johnson and Goldblatt, 2015; Zerkle and Mikhail, 2017; Johnson and Goldblatt, 2017], there is not a consensus on how much $\mathrm{N}$ the Earth contains and how it has moved between different reservoirs over time. In addition, and especially in the Hadean and Archean, a number of parameters that could affect the $\mathrm{N}$ cycle are not well constrained. These include when oxygenic photosynthesis first appeared, the rate of hydrothermal alteration of ocean crust, deep water upwelling, continental weathering, and the initiation of plate tectonics [Van Hunen and Moyen, 2012]. To investigate how changing these poorly constrained parameters may have affected the $\mathrm{N}$ cycle over time, we ran Monte Carlo simulations $(\mathrm{n}=1000)$ where a number of parameters were given random values within a prescribed range (Table 5, Figs. 9-10).

Table 5: Range of values used for Monte Carlo simulartions. PAN is Present Atmospheric Nitrogen, or $4 \times 10^{18} \mathrm{~kg}$

\begin{tabular}{lr} 
Parameter & Range (units) \\
\hline Upwelling & $0.16-16 \mathrm{~Sv}$ \\
Oxygenic photosynthesis start time & $2.4-3 \mathrm{Ga}$ \\
Plate tectonics start time & $3-4 \mathrm{Ga}$ \\
Weathering timescale & $50-500 \mathrm{Myr}$ \\
Hydrothermal flow rate & $0.5-50 \times 10^{16} \mathrm{~L} \mathrm{yr}^{-1}$ \\
Total N & $2-12 \mathrm{PAN}$ \\
Percent starting in atmosphere & $0-100 \%$
\end{tabular}

Strikingly, our model suggests that the amount of $\mathrm{N}$ found in the atmosphere today may in some part be related to the total $\mathrm{N}$ in the planet (Fig. 9). There is a strong correlation between the total $\mathrm{N}$ in the model and the atmospheric $\mathrm{N}$ mass after $4.5 \mathrm{Gyr}$ of planetary evolution. Monte Carlo results that have 1 PAN atmosphere at the present day are those with a total $\mathrm{N}$ budget of $\sim 4-6$ PAN, similar to independent budget estimates [Johnson and Goldblatt, 2015]. On Earth, the atmospheric N content directly relates to the total planetary $\mathrm{N}$ budget. It is possible that this proxy may work for other terrestrial plan- 

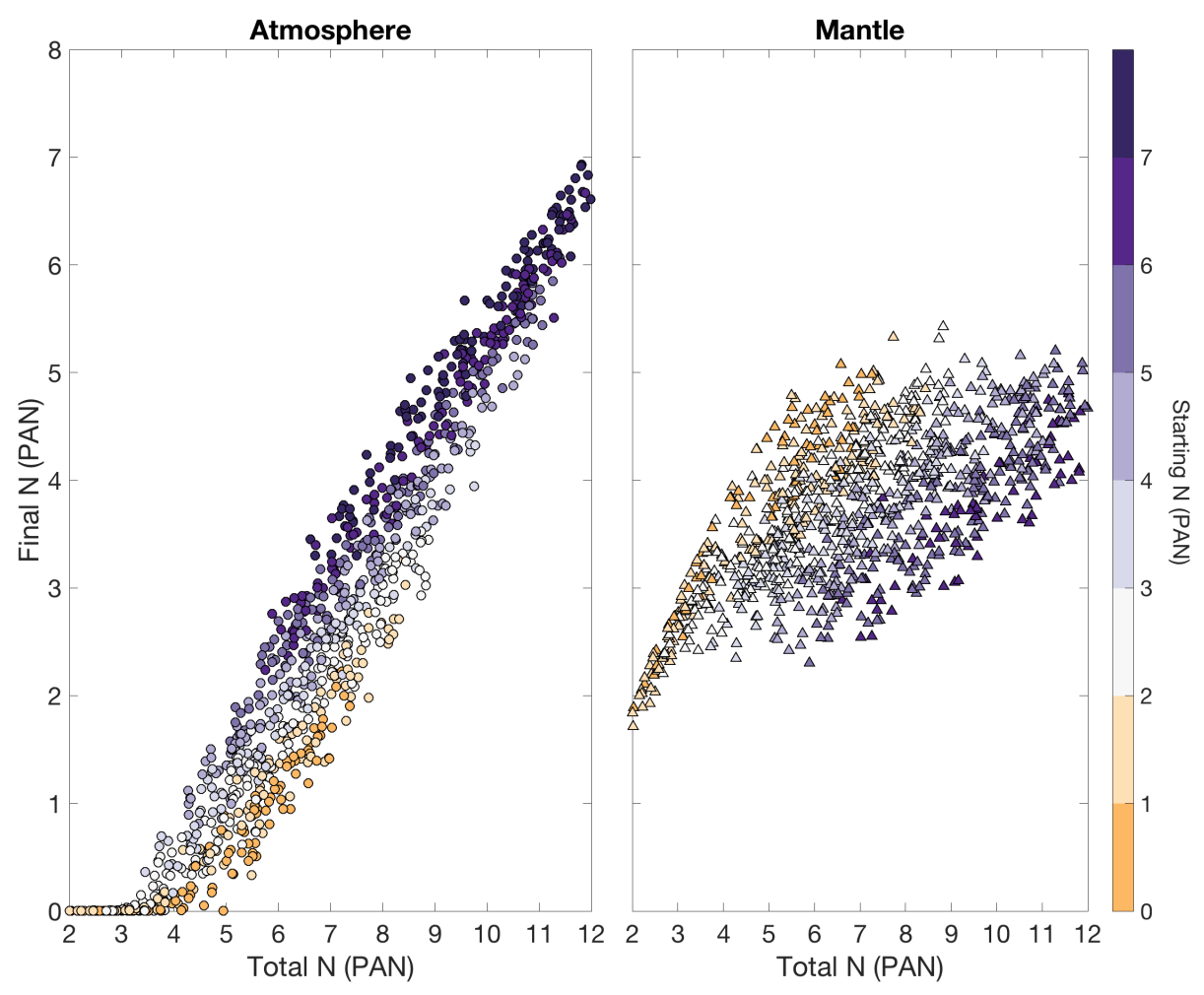

Figure 9: Final atmospheric and mantle $\mathrm{N}$ vs total $\mathrm{N}$ for 1000 Monte Carlo simulations. Note strong correlation between atmospheric $\mathrm{N}$ and total $\mathrm{N}$, and that for very low $\mathrm{N}$ budgets, the atmospheric mass is small. Runs that results in a 1 PAN atmosphere have 5 PAN total $\mathrm{N}$. The mantle saturates at 3 PAN.

ets, given evidence for plate tectonics (e.g., linear mountain belts, bimodal topographies) and biologic $\mathrm{N}$ cycling (e.g., $\mathrm{N}_{2}$ and $\mathrm{O}_{2}$ coexisting, $\mathrm{N}_{2} \mathrm{O}$ ), atmospheric $\mathrm{N}$ could serve as an estimate for total planetary $\mathrm{N}$ content.

The mantle $\mathrm{N}$ content also increases with increasing total content, but tends to "saturate" at 4.5 PAN (Fig. 10). This is because net subduction and outgassing at mid-ocean ridges tend to balance each other, while $\mathrm{N}$-fixing is limited by $\mathrm{PO}_{4}^{3-}$ availability. That is, the rate at which organisms can fix $\mathrm{N}$ is not enough to outpace overall outgassing, thus at higher total $\mathrm{N}$ budgets, $\mathrm{N}$ accumulates in the atmosphere. For very small total $\mathrm{N}$ budgets less than 3 PAN, N-fixing is efficient enough to draw down the atmosphere almost completely into the mantle. 

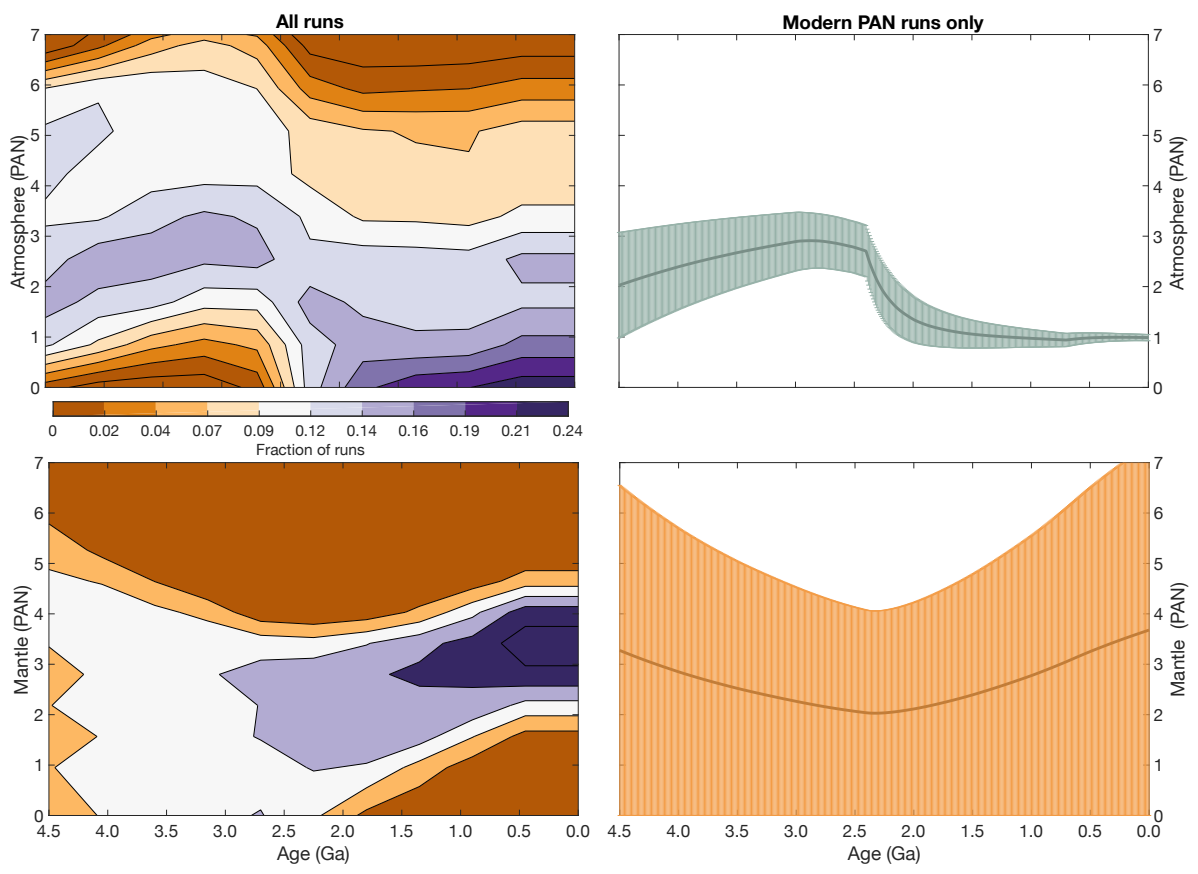

Figure 10: Results of Monte Carlo runs for atmosphere and mantle values through time for all runs (a-b) and just runs that result in a 1 PAN present atmosphere (c-d). Panels c-d show the mean and one standard deviation. The mantle tends to evolve towards a final value of between 3-4 over time, while the atmosphere is more variable. Most runs end with a 2 PAN atmosphere at modern and throughout much of the Proterozoic and Archean, with two other nodes at 0.5 and 4 PAN. Runs that result in a 1 PAN atmosphere start with a $~ 2$ PAN atmosphere at $4.5 \mathrm{Ga}$, and are drawn down in the late Archean. Mantle $\mathrm{N}$ for runs that result in a 1 PAN atmosphere average 4 PAN, but are variable.

In addition, the EarthN model does not thoroughly parameterize mantle evolution over time. Thus, we predict that model output suggesting mantle saturation at 4.5 is a minimum estimate of the true $\mathrm{N}$ content of the mantle.. Previous work has estimated that the mantle has an enormous capacity for $\mathrm{N}$, and could possibly contain many 10s of PAN [Li et al., 2013; Smith et al., 2014; Johnson and Goldblatt, 2015].

Monte Carlo realizations that result in a 1 PAN present atmosphere show the same overall pattern as the nominal run (Fig. 10). On average, the atmosphere starts out with greater than modern mass, then decreases, again likely due to the evolution of oxygenic photosynthesis, in the late Archean. The atmosphere remains at approximately 1 PAN 
throughout the Proterozoic, with a small increase at the NOE, due to enhanced denitrification at this time. Even when we allow for a random total $\mathrm{N}$ and a random amount of $\mathrm{N}$ starting in the atmosphere, the overall trend in the atmospheric evolution is to be drawn down from higher Archean values towards the modern. In contrast, the mantle stays consistent on average, at its saturation of about 4 PAN. The standard deviation shown in Fig. 10-d indicates there are many mantle $\mathrm{N}$ paths which are consistent with the EarthN model evolving a 1 PAN present atmosphere.

As previously mentioned, the temperature history of the mantle, and behavior of $\mathrm{N}$ in different geothermal regimes exerts a strong control on the evolution of $\mathrm{N}$ in the Earth system over time. This behavior also depends on how much temperature actually controls $\mathrm{N}$ volatilization at subduction zones. Studies have shown that redox [Li et al., 2013], temperature/pressure [Li and Keppler, 2014], distribution of $\mathrm{N}$ between fluid and melt [Mallik et al., 2018], and pH [Mikhail and Sverjensky, 2014] also exert control over N speciation and retention in the mantle. The interaction of these different factors in geologic evolution could have had a large effect on $\mathrm{N}$ cycling over Earth history [Mikhail and Howell, 2016]. We predict that redox evolution is likely to have the largest effect on $\mathrm{N}$ processing and storage in the mantle. The upper mantle and mantle lithosphere have, on average, been at their current redox state since $3.5 \mathrm{Ga}$ [Canil, 2002]. Arc basalts, however, are more oxidized than MORBs with otherwise similar chemical composition [Kelley and Cottrell, 2012; Brounce et al., 2014]. In addition, the deeper mantle is more reducing than the upper mantle [Frost and McCammon, 2008].

It follows, then, that $\mathrm{N}$ is more soluble in the reduced lower mantle than the more oxidized upper mantle and subduction zone mantle wedge. As the mantle has become more oxidized through time, $\mathrm{N}$ recycling to the atmosphere would be favored. If the oxidation state of subduction zone mantle has similarly increased through time, this would enhance recycling of $\mathrm{N}$ to the surface [e.g., Mikhail and Sverjensky, 2014]. Thus, there are competing features controlling $\mathrm{N}$ recycling into the mantle: decreasing temperature and increasing $f \mathrm{O}_{2}$. Given observations of net $\mathrm{N}$ retention at modern subduction zones [Li et al., 2007; Mitchell et al., 2010; Halama et al., 2014], we hypothesize that mantle wedge temperature is the dominant control of $\mathrm{N}$ recycling efficiency, at least on the modern Earth. How this balance of redox and temperature has controlled N, and other volatile, recycling over Earth history has important implications for the evolution of the surface and interior of the planet. 
The above discussion highlights a broader point regarding model construction. Herein, we have constructed an Earth system $\mathrm{N}$ cycle model, and presented a nominal run based on plausible assumptions about the Earth through time. The results presented, however, should not be taken as gospel, dogma, or actuality. There are a number of fluxes and factors in the Earth which could affect results of the EarthN model. In addition to mantle chemistry, mantle capacity for $\mathrm{N}$ is enormous [Li et al., 2013], and the great potential size of this reservoir could have major influence over $\mathrm{N}$ cycling during Earth history. The lack of continental ecosystems, and simple treatment of hydrothermal activity in oceanic crust in this model could be important parameters to investigate. The addition of isotopes to the model would allow for predictions that could be tested in the rock record. We envision future studies to explore this wider parameter space, both for specific intervals in time and for grand trends over Earth history.

\section{Conclusions}

We have constructed an Earth system N model, EarthN, that includes biologic and geologic fluxes to predict the distribution of $\mathrm{N}$ in the major reservoirs of the Earth through time. In addition to linking the $\mathrm{N}$ cycle to $\mathrm{PO}_{4}^{3-}$ availability, the model is driven by changing $\mathrm{O}_{2}$ abundance and mantle cooling with plate tectonics. Model output is consistent with movement of $\mathrm{N}$ between the three major reservoirs (atmosphere, mantle, continental crust) in significant amounts over Earth history.

In all model runs, the early part of Earth history, from 4.5-2.8 Ga, is characterized by net mantle outgassing and atmospheric growth. This early history is due to high mantle temperatures and inefficient export production. After the evolution of oxygenic photosynthesis, atmospheric $\mathrm{N}$ is immediately drawn down and sequestered in sediments due to increased export production. At the Great Oxidation Event, increased weathering and nutrient delivery enhances export production, which in turn enhances atmospheric drawdown via $\mathrm{N}$-fixation. Mantle cooling over time, with associated increase in efficiency of $\mathrm{N}$ subduction, facilitates biologically fixed $\mathrm{N}$ to be sequestered into geologic reservoirs over time.

One of the strongest controls on the atmospheric mass of $\mathrm{N}$ through time, and especially the modern mass of the atmosphere, is the total $\mathrm{N}$ in the Bulk Silicate Earth. Monte Carlo simulations that vary a number of parameters (deep water upwelling, hydrothermal 
circulation, oxygenic photosynthesis appearance, weathering timescale, total $\mathrm{N}$ and distribution) that result in a 1 PAN atmosphere after 4.5 Ga of model evolution are most consistent with a total BSE N budget of $\sim 4-6$ PAN. The mantle tends to saturate at 4-4.75 PAN. The mantle is the dominant $\mathrm{N}$ carrier for total $\mathrm{N}$ budgets below 6-7 PAN, while the atmosphere is dominant at higher values.

The EarthN model shows that the distribution of $\mathrm{N}$ in the Earth system through time could have varied significantly. Nominal model runs result in net atmospheric drawdown over time, which is consistent with geochemical proxies. There are a number of controls on $\mathrm{N}$ history, including appearance of oxygenic photosynthesis, mantle cooling, and $\mathrm{N}$ in subduction zones. We anticipate further work in this area to focus on how temperature and redox control $\mathrm{N}$ at subduction zones. Equally, the cycling of $\mathrm{N}$ in the mantle over time is poorly known but crucially important. There is potential for not only investigating Earth history, but exploration of Venus, Mars, and potential exoplanetary targets in the future.

\section{Acknowledgments}

The authors would like to acknowledge Katja Fennel for sharing code. We also acknowledge helpful discussions concerning model development with Rameses D'Souza, Arlan Dirkson, and Christiaan Laureijs at the University of Victoria. Ananya Mallik and one anonymous reviewer are thanked for useful reviews, as is Cyn-Ty Lee for editorial duties.

Supporting model code and output data can be found as a supplemental file with this manuscript. In addition, code will be available at the corresponding author's webpage: www.benwjohnson.com.

BWJ is currently supported by NSF (EAR - 1725784) and was previously supported by NSERC Discovery grant to CZG. CZG is supported by an NSERC Discovery grant.

\section{A: Differential equations}

Based on the above model decsription, we write a series of differential equations to solve for model species in boxes. 


\section{Atmosphere}

$$
\frac{d R_{j}^{\mathrm{atm}}}{d t}=\sum_{i *} F_{\mathrm{as}, \mathrm{j}}^{a t m-i *}+F_{\mathrm{ogarc}, \mathrm{j}}
$$

for $j=\left\{\mathrm{N}_{2},{ }^{40} \mathrm{Ar},{ }^{36} \mathrm{Ar}\right\}$ and $i *$ includes air-sea flux from all shallow ocean boxes ( $\{$ low, high, shelf\}).

\section{Low- and high-latitude shallow ocean}

for $i=\{$ low, high $\}$.

\section{Shelf ocean}




\section{Deep ocean}

$$
\begin{aligned}
\frac{d R_{40 \mathrm{Ar}}^{\text {deep }}}{d t}=F_{\text {mix,40Ar }}^{\text {deep }}+F_{\text {rd }}^{\text {deep }}-F_{\text {hydro,40Ar }}^{\text {deep }}+F_{\text {ogmor,40Ar }} \\
\frac{d R_{36 \mathrm{Ar}}^{\text {deep }}}{d t}=F_{\text {mix,36Ar }}^{\text {deep }}-F_{\text {hydro,36Ar }}^{\text {deep }}+F_{\text {ogmor,36Ar }} \\
\frac{d R_{40 \mathrm{~K}}^{\text {deep }}}{d t}=F_{\text {mix,40K }}^{\text {deep }}-F_{\text {rd }}^{\text {deep }}-F_{\text {hydro,40K }}+F_{\text {ogmor,40K }} \\
\frac{d R_{\mathrm{K}}^{\text {deep }}}{d t}=F_{\text {mix,K }}^{\text {deep }}-F_{\text {hydro,K }}+F_{\text {ogmor,K }} \\
\frac{d R_{\mathrm{PO} 4}^{\text {deep }}}{d t}=F_{\text {mix,PO4 }}^{\text {deep }}+F_{\text {remin,PO4 }}^{\text {deep }}-F_{\text {hydro,PO4 }}+F_{\text {ogmor,PO4 }} \\
\frac{d R_{\mathrm{NO} 3}^{\text {deep }}}{d t}=F_{\text {mix,NO3 }}^{\text {deep }}+F_{\text {remin,NO3 }}^{\text {deep }}+F_{\text {nit }}^{\text {deep }}-F_{\text {den }}^{\text {deep }}-F_{\text {hydro,NO3 }}^{\text {deep }} \\
\frac{d R_{\mathrm{NH} 4}^{\text {deep }}}{d t}=F_{\text {mix,NH4 }}^{\text {deep }}-F_{\text {nit }}^{\text {deep }}+F_{\text {remin,NH4 }}^{\text {deep }}-F_{\text {seddif }}^{\text {deep }}-F_{\text {hydro,NH4 }}^{\text {deep }} \\
\frac{d R_{\mathrm{N} 2}^{\text {deep }}}{d t}=F_{\text {mix,N2 }}^{\text {deep }}+F_{\text {den }}^{\text {deep }}+F_{\text {ogmor,N }}
\end{aligned}
$$

\section{Sediments}

for $i=\{$ reactive shelf sediments, reactive deep sediments $\}, i i=\{$ shelf sediments, deep sediments $\}$, and $i i i=\{$ shelf ocean, deep ocean $\}$.

\section{Ocean crust}

for $i=\{$ ocean crust $\}$. 


\section{Continental crust}

$$
\begin{gathered}
\frac{d R_{40 \mathrm{Ar}}^{i}}{d t}=F_{\mathrm{rd}}^{i}-F_{\mathrm{w}, 40 \mathrm{Ar}} \\
\frac{d R_{40 \mathrm{~K}}^{i}}{d t}=-F_{\mathrm{rd}}^{i}-F_{\mathrm{w}, 40 \mathrm{~K}} \\
\frac{d R_{j}^{i}}{d t}=F_{\mathrm{cg}, \mathrm{j}}-F_{\mathrm{w}, \mathrm{j}} \\
\text { for } i=\{\text { continental crust }\} \text { and } j=\left\{\mathrm{K}, \mathrm{NH}_{4}^{+}, \mathrm{PO}_{4}^{3-}\right\} . \\
\text { Mantle } \\
\frac{d R_{40 \mathrm{Ar}}^{i}}{d t}=F_{\mathrm{rd}}^{i}-F_{\mathrm{ogm}, 40 \mathrm{Ar}}+F_{\text {subnet }, 40 \mathrm{Ar}} \\
\frac{d R_{40 \mathrm{~K}}^{i}}{d t}=-F_{\mathrm{rd}}^{i}-F_{\mathrm{ogm}, 40 \mathrm{~K}}+F_{\text {subnet }, 40 \mathrm{~K}} \\
\frac{d R_{j}^{i}}{d t}=-F_{\mathrm{ogmor}, j}+F_{\mathrm{subnet}, j} \\
\text { for } i=\{\text { mantle }\} \text { and } j=\left\{{ }^{36} \mathrm{Ar}, \mathrm{N}, \mathrm{PO}_{4}^{3-}, \text { and } \mathrm{K}\right\} .
\end{gathered}
$$

\section{B: Calculating initial $\mathbf{N}$ distribution}

We use the following equation from Libourel et al. [2003] to calculate the starting amount of $\mathrm{N}$ in the atmosphere and mantle for the nominal run:

$$
N_{2, \text { magma }}=2.21 \times 10^{-9} \mathrm{pN}_{2}+f O_{2}^{-0.75} 2.13 \times 10^{-17} \mathrm{pN}_{2}^{0.5}
$$

where $\mathrm{pN}_{2}$ is in atmospheres and $N_{2}$, magma is in mol $\mathrm{g}^{-1} \mathrm{~atm}^{-1}$. We chose an $f \mathrm{O}_{2}$ of IW - $2\left(f \mathrm{O}_{2}=10^{-11.4}\right)$, where IW is the iron wüstite buffer, which is the expected oxygen fugacity of the magma ocean immediately after core formation [Wood et al., 2006] (Fig. B.1).

Then, for a variety of $\mathrm{pN}_{2}$ values, we calculate a magma $\mathrm{N}_{2}$ concentration at $f \mathrm{O}_{2}=$ IW-2, and multiply this concentration by the mass of the mantle. This assumes the whole mantle equilibrated during the atmosphere during the magma ocean phase.

Finally, we describe the fraction of the total $\mathrm{N}$ budget that is in the atmosphere based on the above solubility calculations. This figure ultimately guided our choice for total $\mathrm{N}$ budget and starting atmospheric $\mathrm{N}$ mass in the nominal run. We chose 4.5 PAN as the total budget, which results in $82 \%$ of the total $\mathrm{N}$ starting in the atmosphere. The total $\mathrm{N}$ budget was chosen so that the nominal run resulted in a 1 PAN modern atmosphere at the end of the model run. 

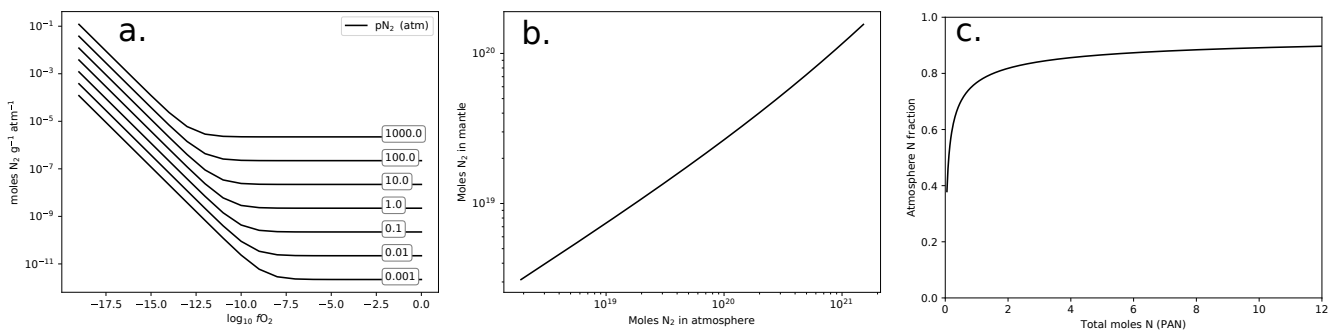

Figure B.1: Nitrogen solubility in basaltic magma used to calculate starting atmospheric N. a.) Basaltic magma $\mathrm{N}_{2}$ content as a function of oxygen fugacity. Lines are for different $\mathrm{pN}_{2}$, with pressure in atmospheres shown in boxes. Modified after Libourel et al. [2003]. b.) Total mantle and atmospheric $\mathrm{N}$ based on the solubility experiments of Libourel et al. [2003] at the end of core formation. c.) Atmospheric fraction of $\mathrm{N}$ as a function of total $\mathrm{N}$ (PAN) for an atmosphere in equilibrium with the mantle at the end of the magma ocean phase. Oxygen fugacity is IW -2 .

\section{C: Argon and potassium model performance checks}

We use argon concentration in the atmosphere as a check on the performance of degassing and air-sea gas exchange in the model. The model overestimates the modern day ratio of ${ }^{40} \mathrm{Ar} /{ }^{36} \mathrm{Ar}$ in the atmosphere by about 1.5 fold (Fig. C.1). It is possible that this slight overestimate is due in part to the model underestimating $\mathrm{K}$ concentration in the continental crust (Fig. C.1). Higher K-content in the crust would lead to more ${ }^{40} \mathrm{Ar}$ in the crust, through storage after radioactive decay of ${ }^{40} \mathrm{~K}$, and would then lower the atmospheric Ar-ratio.

While the model output reproduces the $\mathrm{K}$ content of the mantle well, it underestimates the continental crust concentration. Weathering is simply proportional to concentration in the model, and does not take into account either differences in weathering due to biologic activity or continental growth over time. Given different amounts of crustal growth over time [e.g., Dhuime et al., 2012], the continents would evolve in their capacity to store $\mathrm{K}$ over time. In addition, we do not consider the effects of continental lithospheric roots or cratonic mass, which could serve to store $\mathrm{K}$ for long periods during Earth history. Future iterations of the EarthN model should incorporate crustal growth scenarios. 

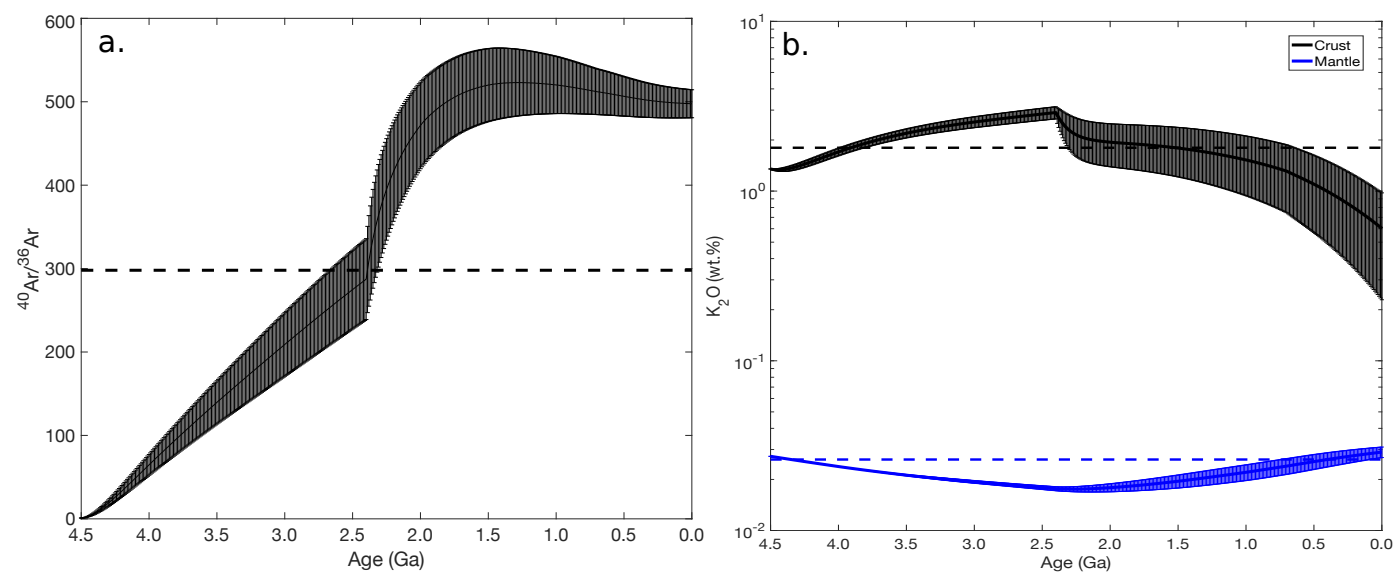

Figure C.1: Atmospheric ${ }^{40} \mathrm{Ar} /{ }^{36} \mathrm{Ar}$ and $\mathrm{K}$ concentrations (wt. $\% \mathrm{~K}_{2} \mathrm{O}$ ) for continental crust and mantle from Monte Carlo runs. The mean and one standard deviation are shown, and modern values are given as dashed line [Rudnick and Gao, 2014; Arevalo et al., 2013].

\section{References}

Anbar, A. D., Y. Duan, T. W. Lyons, G. L. Arnold, B. Kendall, R. A. Creaser, A. J. Kaufman, G. W. Gordon, C. Scott, J. Garvin, et al. (2007), A whiff of oxygen before the great oxidation event?, Science, 317(5846), 1903-1906, doi:10.1126/science.1140325.

Arevalo, R., W. F. McDonough, A. Stracke, M. Willbold, T. J. Ireland, and R. J. Walker (2013), Simplified mantle architecture and distribution of radiogenic power, Geochemistry, Geophysics, Geosystems, 14(7), 2265-2285, doi:http://dx.doi.org/10.1002/ggge. 20152.

Barry, P., and D. Hilton (2016), Release of subducted sedimentary nitrogen throughout Earth's mantle, Geochemical Perspectives Letters, 2, 148-159.

Bebout, G., and M. Fogel (1992), Nitrogen-isotope compositions of metasedimentary rocks in the Catalina Schist, California: implications for metamorphic devolatilization history, Geochimica et Cosmochimica Acta, 56(7), 2839-2849, doi:http://dx.doi.org/10.1016/ 0016-7037(92)90363-N.

Bebout, G. E., K. E. Lazzeri, and C. A. Geiger (2015), Pathways for nitrogen cycling in the Earth's crust and upper mantle: A review and new results for microporous beryl and cordierite, American Mineralogist, doi:http://dx.doi.org/10.2138/am-2015-5363.

Berner, R. A. (2006), Geological nitrogen cycle and atmospheric $\mathrm{N}_{2}$ over phanerozoic time, Geology, 34(5), 413-415, doi:http://dx.doi.org/10.1130/G22470.1. 
Boyd, S. (2001), Nitrogen in future biosphere studies, Chemical Geology, 176(1), 1-30, doi:http://dx.doi.org/10.1016/S0009-2541(00)00405-8.

Bradley, D. C. (2008), Passive margins through earth history, Earth-Science Reviews, 91(1), 1-26, doi:http://dx.doi.org/10.1016/j.earscirev.2008.08.001.

Bristow, L. A., T. Dalsgaard, L. Tiano, D. B. Mills, A. D. Bertagnolli, J. J. Wright, S. J. Hallam, O. Ulloa, D. E. Canfield, N. P. Revsbech, et al. (2016), Ammonium and nitrite oxidation at nanomolar oxygen concentrations in oxygen minimum zone waters, Proceedings of the National Academy of Sciences, 113(38), 10,601-10,606, doi: http://dx.doi.org/10.1073/pnas.1600359113.

Brounce, M., K. Kelley, and E. Cottrell (2014), Variations in $\mathrm{Fe}^{3+} / \Sigma \mathrm{Fe}$ of Mariana Arc Basalts and Mantle Wedge $f \mathrm{O}_{2}$, Journal of Petrology, 55(12), 2513-2536.

Buick, R. (2008), When did oxygenic photosynthesis evolve?, Philosophical Transactions of the Royal Society of London B: Biological Sciences, 363(1504), 2731-2743.

Busigny, V., P. Cartigny, and P. Philippot (2011), Nitrogen isotopes in ophiolitic metagabbros: A re-evaluation of modern nitrogen fluxes in subduction zones and implication for the early earth atmosphere, Geochimica et Cosmochimica Acta, 75, 7502-7521, doi: http://dx.doi.org/10.1016/j.gca.2011.09.049.

Canil, D. (2002), Vanadium in peridotites, mantle redox and tectonic environments: Archean to present, Earth and Planetary Science Letters, 195(1), 75-90, doi:http: //dx.doi.org/10.1016/S0012-821X(01)00582-9.

Catling, D. C., and J. F. Kasting (2017), Atmospheric evolution on inhabited and lifeless worlds, Cambridge University Press.

Condie, K. C. (2013), Plate tectonics \& crustal evolution, Elsevier.

Crowe, S. A., D. E. Canfield, A. Mucci, B. Sundby, and R. Maranger (2012), Anammox, denitrification and fixed-nitrogen removal in sediments from the lower st. lawrence estuary, Biogeosciences, 9(11), 4309-4321.

Dalsgaard, T., F. J. Stewart, B. Thamdrup, L. D. Brabandere, N. P. Revsbech, O. Ulloa, D. E. Canfield, and E. F. DeLong (2014), Oxygen at nanomolar levels reversibly suppresses process rates and gene expression in anammox and denitrification in the oygen minimum zone off Northern Chile, mBio, 5, e01,966-14.

Delwiche, C. (1977), Energy relations in the global nitrogen cycle, Ambio, pp. 106-111. Dhuime, B., C. Hawkesworth, P. Cawood, and C. Stoery (2012), A change in the geodynamics of continental growth 3 billion years ago, Science, 335, 1334-1336, doi: 
http://dx.doi.org/10.1126/science.1216066.

Elderfield, H., and A. Schultz (1996), Mid-ocean ridge hydrothermal fluxes and the chemical composition of the ocean, Annual Review of Earth and Planetary Sciences, 24(1), $191-224$.

Elkins, L., T. Fischer, D. Hilton, Z. Sharp, S. McKnight, and J. Walker (2006), Tracing nitrogen in volcanic and geothermal volatiles from the Nicaraguan volcanic front, Geochimica et Cosmochimica Acta, 70(20), 5215-5235, doi:http://dx.doi.org/10.1016/j. gca.2006.07.024.

Evrard, V., R. N. Glud, and P. L. Cook (2013), The kinetics of denitrification in permeable sediments, Biogeochemistry, 113, 563-572, doi:10.1007/s10533-012-9789-x.

Farquhar, J., Jhar, H. Bao, and M. Thiemens (2000), Atmospheric influence of Earth's earliest sulfur cycle, Science, 289, 756-758, doi:http://dx.doi.org/10.1126/science.289.5480. 756.

Fennel, K., M. Follows, and P. G. Falkowski (2005), The co-evolution of the nitrogen, carbon and oxygen cycles in the proterozoic ocean, American Journal of Science, 305(6-8), 526-545, doi:http://dx.doi.org/10.2475/ajs.305.6-8.526.

Fischer, T., D. Hilton, M. Zimmer, A. Shaw, Z. Sharp, and J. Walker (2002), Subduction and recycling of nitrogen along the Central American margin, Science, 297(5584), 1154-1157, doi:http://dx.doi.org/10.1126/science.1073995.

Frost, D., and C. McCammon (2008), The redox state of Earth's mantle, Annual Review of Earth and Planetary Sciences, 36, 389-420, doi:http://dx.doi.org/10.1146/annurev.earth. 36.031207 .124322 .

Garcia, H., R. Locarnini, T. Boyer, J. Antonov, O. Baranova, M. Zweng, J. Reagan, and D. Johnson (2014), Dissolved inorganic nutrients (phosphate, nitrate, silicate), World Ocean Atlas, 4, 25.

German, C., and W. Seyfried (2014), Hydrothermal processes., Treatise on Geochemistry, $191-233$.

Goering, J. J. (1985), Marine denitrification, in Denitrification in the nitrogen cycle, pp. 191-224, Springer.

Goldblatt, C., T. Lenton, and A. Watson (2006), Bistability of atmospheric oxygen and the Great Oxidation, Nature, 443(7112), 683-686.

Goldblatt, C., M. Claire, T. Lenton, A. Matthews, A. Watson, and K. Zahnle (2009), Nitrogen-enhanced greenhouse warming on early Earth, Nature Geoscience, 2(12), 891- 
896, doi:http://dx.doi.org/10.1038/ngeo692.

Gruber, N. (2008), The marine nitrogen cycle: overview and challenges, Nitrogen in the marine environment, 2, 1-50.

Gruber, N., and J. Galloway (2008), An Earth-system perspective of the global nitrogen cycle, Nature, 451(7176), 293-296.

Halama, R., G. Bebout, T. John, and M. Scambelluri (2014), Nitrogen recycling in subducted mantle rocks and implications for the global nitrogen cycle, International Journal of Earth Sciences, pp. 1-19, doi:http://dx.doi.org/10.1007/s00531-012-0782-3.

Halliday, A. N. (2013), The origins of volatiles in the terrestrial planets, Geochimica et Cosmochimica Acta, 105, 146-171, doi:http://dx.doi.org/10.1016/j.gca.2012.11.015.

Haynes, W., T. Bruno, and D. Lide (Eds.) (2014), CRC Handbook of Chemistry and Physics 95, CRC Press.

Hofmann, H., K. Grey, A. Hickman, and R. Thorpe (1999), Origin of 3.45 Ga coniform stromatolites in Warrawoona group, Western Australia, Geological Society of America Bulletin, 111(8), 1256-1262.

Houlton, B., S. Morford, and R. Dahlgren (2018), Convergent evidence for widespread rock nitrogen sources in Earth's surface environment, Science, 360(6384), 58-62.

Johnson, B. W., and C. Goldblatt (2015), The nitrogen budget of earth, Earth Science Reviews, 148, 150-173, doi:http://dx.doi.org/10.1016/j.earscirev.2015.05.006.

Johnson, B. W., and C. Goldblatt (2017), A secular increase in continental crust nitrogen during the Precambrian, Geochemical Perspectives Letters, 4, 24-28.

Kelley, K. A., and E. Cottrell (2012), The influence of magmatic differentiation on the oxidation state of Fe in a basaltic arc magma, Earth and Planetary Science Letters, 329, $109-121$.

Klingler, J., R. Mancinelli, and M. White (1989), Biological nitrogen fixation under primordial martian partial pressures of dinitrogen, Advances in Space Research, 9(6), 173176, doi:http://dx.doi.org/10.1016/0273-1177(89)90225-1.

Korenaga, J. (2010), Scaling of plate tectonic convection with pseudoplastic rheology, Journal of Geophysical Research: Solid Earth (1978-2012), 115(B11), doi:http://dx.doi. org/10.1029/2010JB007670.

Laneuville, M., M. Kameya, and H. J. Cleaves (2018), Earth Without Life: A Systems Model of a Global Abiotic Nitrogen Cycle, Astrobiology. 
Li, L., G. Bebout, and B. Idleman (2007), Nitrogen concentration and $\delta^{15} \mathrm{~N}$ of altered oceanic crust obtained on ODP Legs 129 and 185: Insights into alteration-related nitrogen enrichment and the nitrogen subduction budget, Geochimica et Cosmochimica Acta, 71, 2344-2360, doi:http://dx.doi.org/10.1016/j.gca.2007.02.001.

Li, Y., and H. Keppler (2014), Nitrogen speciation in mantle and crustal fluids, Geochimica et Cosmochimica Acta, 129, 13-32, doi:http://dx.doi.org/10.1016/j.gca.2013.12.031.

Li, Y., R. Huang, M. Wiedenbeck, and H. Keppler (2015), Nitrogen distribution between aqueous fluids and silicate melts, Earth and Planetary Science Letters, 411, 218-228, doi:http://dx.doi.org/10.1016/j.epsl.2014.11.050.

Li, Y., M. Wiedenbeck, S. Shcheka, and H. Keppler (2013), Nitrogen solubility in upper mantle minerals, Earth and Planetary Science Letters, 377, 311-323, doi:http://dx.doi. org/10.1016/j.eps1.2013.07.013.

Li, Y., B. Marty, S. Shcheka, L. Zimmermann, and H. Keppler (2016), Nitrogen isotope fractionation during terrestrial core-mantle separation, Geochemical Perspectives Letters, 2(2), 138-147, doi:10.7185/geochemlet.1614.

Libourel, G., B. Marty, and F. Humbert (2003), Nitrogen solubility in basaltic melt. Part I. Effect of oxygen fugacity, Geochimica et Cosmochimica Acta, 67(21), 4123-4135, doi: http://dx.doi.org/10.1016/S0016-7037(03)00259-X.

Liss, P., and P. Slater (1974), Flux of Gases across the Air-Sea Interface, Nature, 247, $181-184$.

Lyons, T. W., C. T. Reinhard, and N. J. Planavsky (2014), The rise of oxygen in Earth's early ocean and atmosphere, Nature, 506(7488), 307-315.

Mallik, A., Y. Li, and M. Wiedenbeck (2018), Nitrogen evolution within the Earth's atmosphere-mantle system assessed by recycling in subduction zones, Earth and Planetary Science Letters, 482, 556-566.

Marty, B. (2012), The origins and concentrations of water, carbon, nitrogen and noble gases on Earth, Earth and Planetary Science Letters, 313, 56-66, doi:http://dx.doi.org/ 10.1016/j.epsl.2011.10.040.

Marty, B., L. Zimmermann, M. Pujol, R. Burgess, and P. Philippot (2013), Nitrogen isotopic composition and density of the Archean atmosphere., Science, 342, 101-104, doi: http://dx.doi.org/10.1126/science.1240971.

Mikhail, S., and D. Howell (2016), Outlooks in Earth and Planetary Materials: Chemistry and Mineralogy of Earth's Mantle: A petrological assessment of diamond as a recorder 
of the mantle nitrogen cycle, American Mineralogist, 101(4), 780-787.

Mikhail, S., and D. A. Sverjensky (2014), Nitrogen speciation in upper mantle fluids and the origin of Earth's nitrogen-rich atmosphere, Nature Geoscience, 7, 816-819, doi:http: //dx.doi.org/10.1038/ngeo2271.

Mitchell, E. C., T. P. Fischer, D. R. Hilton, E. H. Hauri, A. M. Shaw, J. M. de Moor, Z. D. Sharp, and K. Kazahaya (2010), Nitrogen sources and recycling at subduction zones: Insights from the Izu-Bonin-Mariana arc, Geochemistry, Geophysics, Geosystems, 11(2), doi:http://dx.doi.org/10.1029/2009GC002783.

Nance, R. D., and J. B. Murphy (2013), Origins of the supercontinent cycle, Geoscience Frontiers, 4(4), 439-448.

Navarro-González, R., C. P. McKay, and D. N. Mvondo (2001), A possible nitrogen crisis for Archaean life due to reduced nitrogen fixation by lightning, Nature, 412(6842), 61.

Nishizawa, M., Y. Sano, Y. Ueno, and S. Maruyama (2007), Speciation and isotope ratios of nitrogen in fluid inclusions from seafloor hydrothermal deposits at $3.5 \mathrm{Ga}$, Earth and Planetary Science Letters, 254(3), 332-344, doi:http://dx.doi.org/10.1016/j.eps1.2006.11. 044.

Padhi, C. M., J. Korenaga, and M. Ozima (2012), Thermal evolution of Earth with xenon degassing: a self-consistent approach, Earth and Planetary Science Letters, 341, 1-9, doi:http://dx.doi.org/10.1016/j.epsl.2012.06.013.

Planavsky, N. J., C. T. Reinhard, X. Wang, D. Thomson, P. McGoldrick, R. H. Rainbird, T. Johnson, W. W. Fischer, and T. W. Lyons (2014), Low Mid-Proterozoic atmospheric oxygen levels and the delayed rise of animals, Science, 346(6209), 635-638.

Reinhard, C. T., N. J. Planavsky, S. L. Olson, T. W. Lyons, and D. H. Erwin (2016), Earth's oxygen cycle and the evolution of animal life, Proceedings of the National Academy of Sciences, p. 201521544.

Rudnick, R., and S. Gao (2014), Composition of the Continental Crust, Treatise on Geochemistry, 4, 1-69, doi:http://dx.doi.org/10.1016/S0016-7037(00)00393-8.

Sander, R. (1999), Compilation of Henry`s law constants for inorganic and organic species of potential importance in environmental chemistry, Max-Planck Institute of Chemistry, Air Chemistry Department Mainz, Germany, doi:http://www.mpch-mainz.mpg. de/ sander/res/henry.html.

Sandu, C., A. Lenardic, and P. McGovern (2011), The effects of deep water cycling on planetary thermal evolution, Journal of Geophysical Research, 116, 1-15, doi:http://dx. 
doi.org/10.1029/2011JB008405.

Sleep, N. H., and B. F. Windley (1982), Archean plate tectonics: constraints and inferences, The Journal of Geology, 90(4), 363-379.

Smith, E. M., M. G. Kopylova, and W. Peck (2014), Implications of metallic iron for diamonds and nitrogen in the sublithospheric mantle, Canadian Journal of Earth Sciences, 51(5), 510-516, doi:http://dx.doi.org/10.1139/cjes-2013-0218.

Som, S. M., D. C. Catling, J. P. Harnmeijer, P. M. Polivka, and R. Buick (2012), Air density 2.7 billion years ago limited to less than twice modern levels by fossil raindrop imprints, Nature, 484(7394), 359-362, doi:http://dx.doi.org/10.1038/nature10890.

Som, S. M., R. Buick, J. W. Hagadorn, T. S. Blake, J. M. Perreault, J. P. Harnmeijer, and D. C. Catling (2016), Earth's air pressure 2.7 billion years ago constrained to less than half of modern levels, Nature Geoscience, 9, 448-451.

Stüeken, E., R. Buick, B. M. Guy, and M. C. Koehler (2015), Isotopic evidence for biological nitrogen fixation by molybdenum-nitrogenase from 3.2 Gyr, Nature, doi: http://dx.doi.org/10.1038/nature14180.

Stüeken, E., M. Kipp, M. Koehler, E. Schwieterman, B. W. Johnson, and R. Buick (2016), Modeling pN2 through geologic time: Implications for atmospheric biosignatures, Astrobiology, 16(12), 949-963.

Tolstikhin, I., and B. Marty (1998), The evolution of terrestrial volatiles: a view from helium, neon, argon and nitrogen isotope modelling, Chemical Geology, 147(1-2), 27-52.

Van Hunen, J., and J.-F. Moyen (2012), Archean subduction: fact or fiction?, Annual Review of Earth and Planetary Sciences, 40, 195-219.

Vitousek, P. M., D. N. Menge, S. C. Reed, and C. C. Cleveland (2013), Biological nitrogen fixation: rates, patterns and ecological controls in terrestrial ecosystems, Philosophical Transactions of the Royal Society of London B: Biological Sciences, 368(1621), 20130,119 .

Watenphul, A., B. Wunder, and W. Heinrich (2009), High-pressure ammonium-bearing silicates: Implications for nitrogen and hydrogen storage in the Earth's mantle, American Mineralogist, 94(2-3), 283-292, doi:http://dx.doi.org/10.2138/am.2009.2995.

Watenphul, A., B. Wunder, R. Wirth, and W. Heinrich (2010), Ammonium-bearing clinopyroxene: A potential nitrogen reservoir in the Earth's mantle, Chemical Geology, 270(1), 240-248, doi:http://dx.doi.org/10.1016/j.chemgeo.2009.12.003. 
Winter, J. D. (2001), An introduction to igneous and metamorphic petrology, vol. 697, Prentice Hall New Jersey.

Wood, B. J., M. J. Walter, and J. Wade (2006), Accretion of the Earth and segregation of its core, Nature, 441(7095), 825-833.

Wordsworth, R., and R. Pierrehumbert (2013), Hydrogen-nitrogen greenhouse warming in earth's early atmosphere, Science, 339(6115), 64-67.

Yoshioka, T., M. Wiedenbeck, S. Shcheka, and H. Keppler (2018), Nitrogen solubility in the deep mantle and the origin of Earth's primordial nitrogen budget, Earth and Planetary Science Letters, 488, 134-143.

Zelenski, M., Y. A. Taran, E. Dubinina, E. Polyntseva, et al. (2012), Sources of volatiles for a subduction zone volcano: Mutnovsky volcano, Kamchatka, Geochemistry International, 50(6), 502-521.

Zerkle, A., and S. Mikhail (2017), The geobiological nitrogen cycle: From microbes to the mantle, Geobiology, 15, 343-352.

Zhang, S., X. Wang, H. Wang, C. J. Bjerrum, E. U. Hammarlund, M. M. Costa, J. N. Connelly, B. Zhang, J. Su, and D. E. Canfield (2016), Sufficient oxygen for animal respiration 1,400 million years ago, Proceedings of the National Academy of Sciences, 113(7), 1731-1736.

Zhang, Y., and A. Zindler (1993), Distribution and evolution of carbon and nitrogen in Earth, Earth and Planetary Science Letters, 117(3), 331-345. 